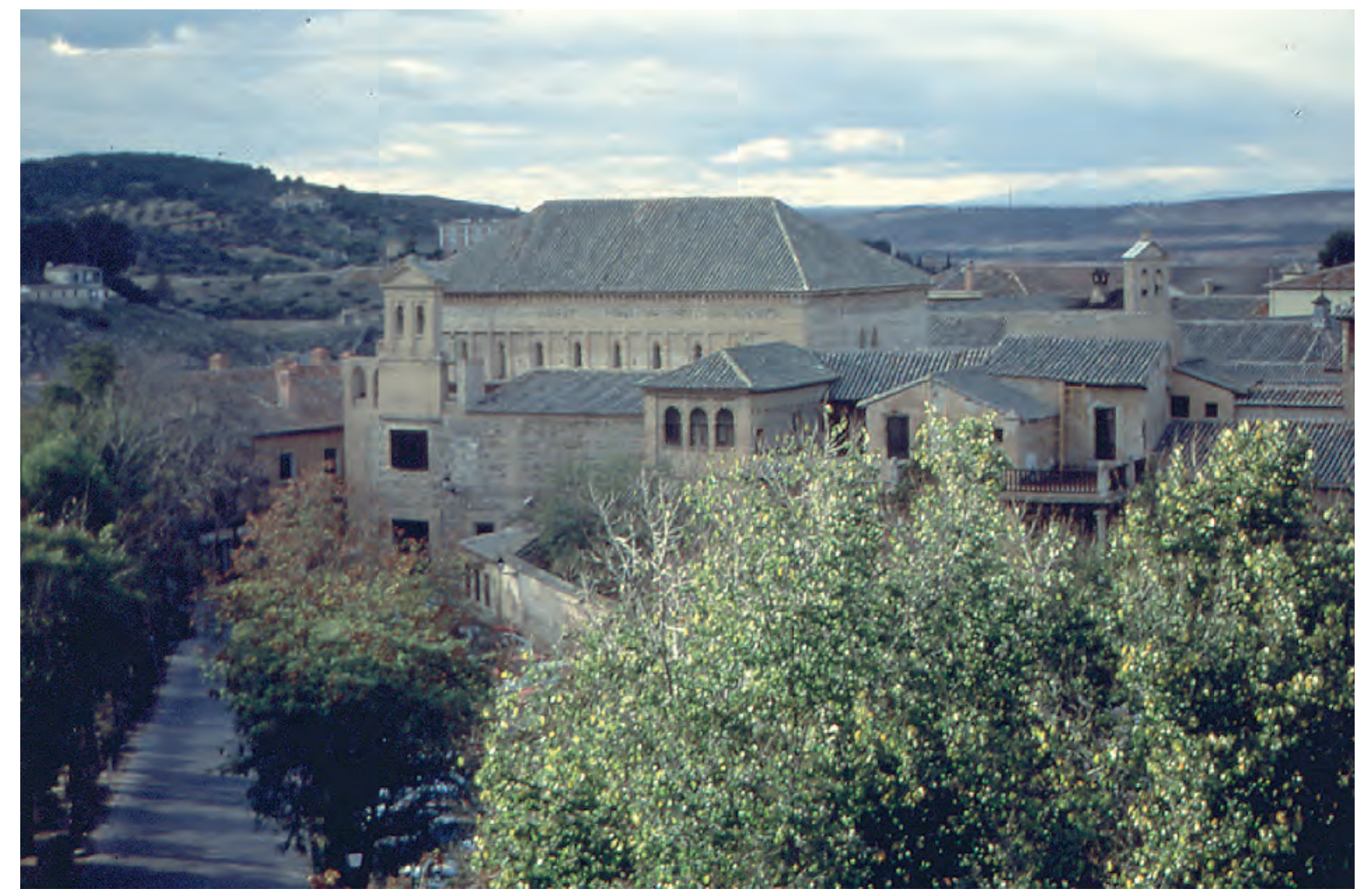

Visión de la Sinagoga restaurada entre el tejido urbano que la rodea

\title{
La Sinagoga del Tránsito Rehabilitación del Museo Sefardí. Toledo
}

\author{
Carmen Bravo Durá \\ Jaime Martínez Ramos
}

Pocas veces, -dicen los arquitectos Carmen Bravo y Jaime Martínez autores de la restauración y del artículo-, cuando se recurre a edificios históricos para museos, ha estado tan claro que el continente superase al contenido, no por el menor valor de éste, sino por el enorme valor de aquél. El objetivo principal de la restauración es plantear el edificio como un objeto de museo en sí mismo, recuperando espacios, iluminación y recorridos. La intervención realizada elimina patologías constructivas en el edificio, restaura su espacialidad y elementos, resuelve su funcionalidad como museo y le dota de las instalaciones necesarias, todo ello sin forzar el edificio, respetando su historicidad.
Synagogue del Tránsito. Rehabilitation of the Sephardi Museum. According to architects Carmen Bravo and Jaime Martínez, authors of the restoration and this article, seldom have there been cases of historic buildings used as museums in which the container surpasses the content, not because of the latter's lack of value, but because of the enormous value of the former. The main aim of restoration is to approach the building as a museum-piece in its own right, recovering spaces, illumination and circulation. The intervention eliminates constructive pathologies on the building, restores space, resolves its functionality as a museum and provides new installations, not altering the museum but respecting its historic value. 
Ocupando el borde Suroeste de la ciudad de Toledo, donde la orografía justifica el nombre del río que la envuelve, el Tajo, y frente al Puente de San Martín, se ubicaba antiguamente la judería. Casi en el centro, aunque un poco al borde de su forma alargada, se sitúa la Sinagoga del Tránsito. Ésta formaba parte, o era colindante, del Palacio de Samuel Ha Leví que se levantaba en los terrenos donde en la actualidad se encuentra la llamada "Casa del Greco". En la Sinagoga, desde 1.971, está instalado el Museo Sefardí.

A diferencia de los edificios de nuestra cultura religiosa, la Sinagoga del Tránsito poco destaca en su exterior, con excepción de su volumen, del magma residencial que la rodea (fig. encabezamiento). Se presenta como una construcción de tres cuerpos. Alto y potente el central, con una gran cubierta a cuatro aguas, que emerge sobre el resto de los edificios de su entorno. Adosados a él, y de menor altura, los otros dos. Pocos elementos la presentan como edificio público. E incluso, alguno de ellos, como la espadaña de dudosa implantación, producen una lectura equívoca. Los huecos de los paramentos, domésticos como si de vivienda se tratara, no predicen el interior. Tan sólo los de la fachada Oeste, por su composición, estructura y orden sugieren lo que el resto de ellos no provocan.

El interior, rotundo, ofrece una impresionante Sala, ricamente decorada con yeserías en sus paramentos, coronada por ventanas de arcos polilobulados en todo su perímetro que la iluminan tenuemente, y rematada con una gran artesa que explica el elevado volumen de la cubierta que se percibe desde el exterior.

\section{ACERCAMIENTO AL EDIFICIO: CULTO Y TIPOLOGÍA}

Está claro que la Sinagoga, como lugar de culto y reunión del pueblo judío, no ha tenido nunca una tipología propia. Ha adoptado siempre las formas y construcciones, así como elementos decorativos, del medio en el que vivían las comunidades judías, en época o lugar. En cuanto a las medievales, las hay de planta cuadrada (Córdoba), de dos naves (Regensburg), de tres (Bembibre). Muy cercanas, en la misma calle, la Sinagoga de Santa María la Blanca y la del Tránsito son ejemplo claro de lo anterior. La primera es una construcción de cinco naves, basilical, con decoración propia de la época, pero austera. La segunda, por su forma, proporciones y decoración, se asemeja más a un rico Salón de un lujoso palacio que a lugar de oración. Esta riqueza interior es el motivo por el que los historiadores han elucubrado sobre si la Sinagoga del Tránsito formaría parte del palacio de Samuel Ha Leví, incluso con entrada directa, o sería independiente de él.

Por otro lado, aunque la comunidad judía estuviera suficientemente integrada en la colectividad, y en el caso concreto que nos ocupa la propia Sinagoga es una demostración palpable de ello, no hay que negar la marginalidad, e incluso, persecución, que dicho grupo sufría. Esto explica el aspecto exterior poco significativo de sus centros religiosos. El mismo papa Alejandro III en el año 1.180 impuso severas restricciones a la apariencia externa de los lugares de culto hebreos.

El culto se realizaba en la Sinagoga mediante la lectura y estudio de la Ley.
1. Planta baja del conjunto: los tres cuerpos de la Sinagoga; el pabellón anexo separado; el patio trasero con los aseos; el jardín exterior

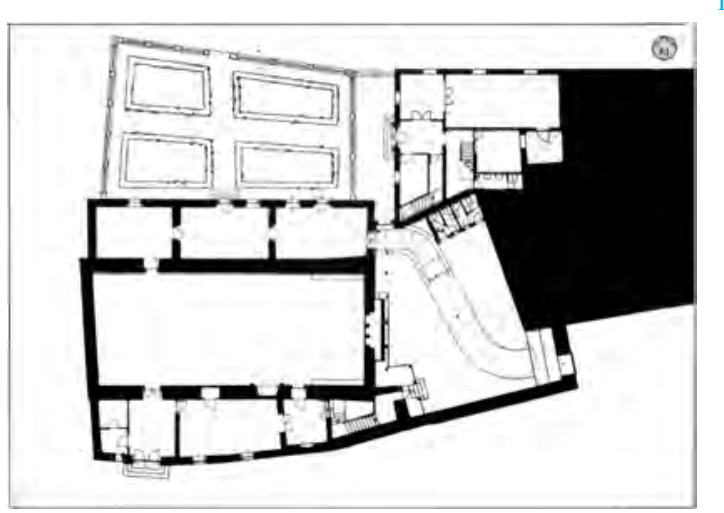




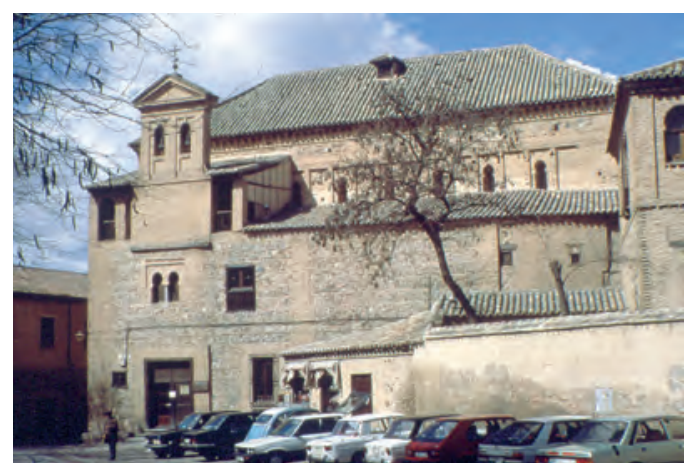

2
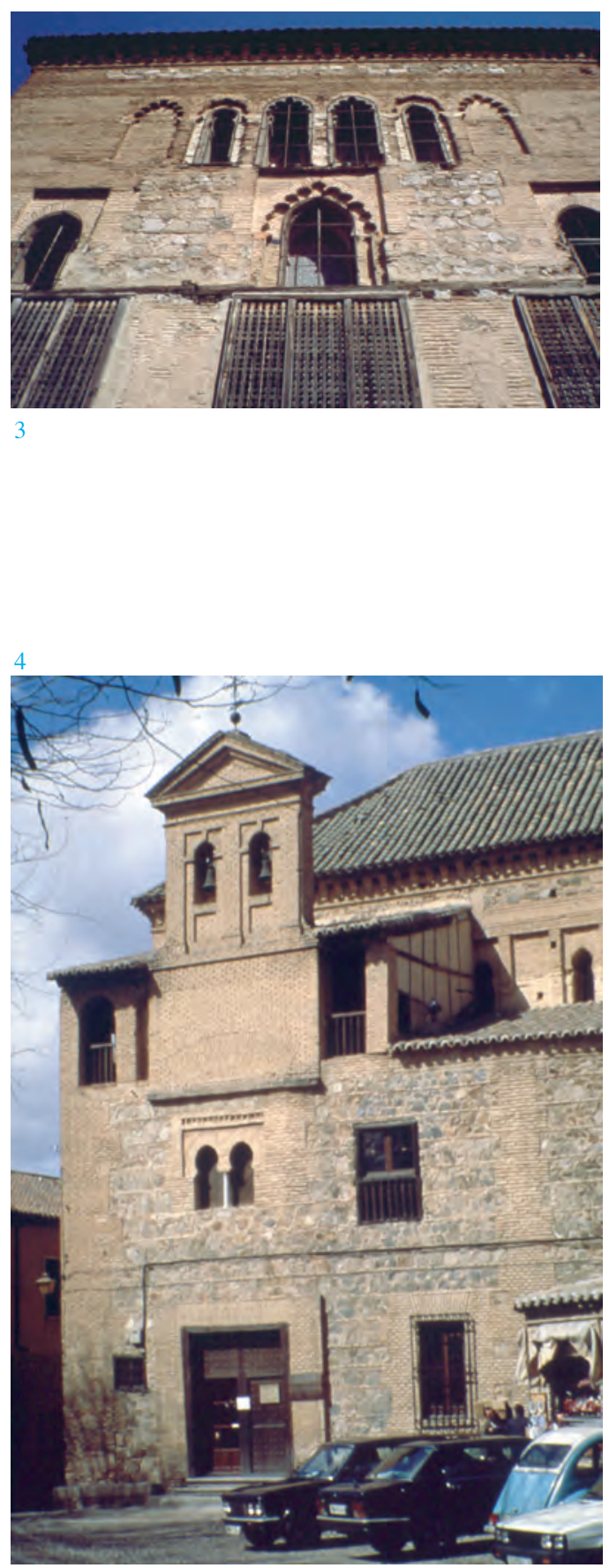

Como en otras religiones, las mujeres asistían al acto en zonas especialmente dedicadas a ellas y separadas de los hombres. Una vez realizada la lectura, la Ley escrita, o Tohra, se guardaba en el "Hejal", armario o habitación destinado exclusivamente a este uso y cuyo interior se protegía de las vistas mediante un tapiz o una cortina. Esta acción no requiere necesariamente de un espacio direccional, pero el hecho de enfatizar el Hejal como elemento importante, junto a que éste se encuentre siempre en el paramento Este, confiere cierta direccionalidad al espacio. Este hecho se manifiesta con mayor o menor potencia según la tipología elegida. Así, es fuerte en Santa María La Blanca por sus planos de arquerías dirigidos hacia el Hejal, o pequeña en la de Córdoba por ser ésta de planta casi cuadrada.

Mero lugar de culto o pieza palaciega, está datado que la Sinagoga del Tránsito, la "gran Sinagoga de Toledo" según Lambert, se funda en 1.357 por Samuel Ha-Levi Abulaifa, tesorero y consejero privado del rey Pedro I el Cruel, que, acusado de defraudador, fue sometido a tormento, muriendo por esta causa en 1.360. Tras la expulsión de los judíos en 1.492, los Reyes Católicos la donan a la Orden de Calatrava que la transforman en Iglesia dedicada a San Benito, sirviendo como asilo y cobijo de caballeros calatravos. Posteriormente, se convierte en simple ermita bajo la advocación del Tránsito de la Virgen, nombre con el que llega hasta nuestros días. Capilla o ermita, con sus dependencias aledañas usadas como archivo, vivienda del capellán, barracón militar, y otros usos variopintos, el valor artístico de la Sala y el histórico del conjunto, hacen que la Sinagoga sea declarada Monumento Nacional en 1.887.

Tras esta declaración se efectúan diversos trabajos de restauración, poco rigurosos algunos, por la escasa documentación de apoyo, y lógicos otros debido a una correcta interpretación arquitectónica. En 1.911, y a petición del Marqués de la Vega Inclán, se incorpora el recién fundado Monumento al Patronato de la Casa del Greco. Entre 1.969 y 1.971 se realizan diversas obras para instalar el Museo Sefardí, que se inaugura en ese mismo año.

Transcurridos tan sólo quince años, la Dirección General de Museos del Estado, de la que depende el Museo Sefardí, decide acometer las obras necesarias para corregir los múltiples daños físicos que aún perduran, así como dotar al museo de las infraestructuras necesarias para su buen funcionamiento. A tal efecto, nos solicita un Informe que recoja las deficiencias encontradas y un posterior Proyecto que formule las intervenciones necesarias.

\section{RECONOCIMIENTO Y DESCRIPCIÓN}

\section{Exterior}

Como ya hemos anticipado, la Sinagoga es una contrucción de tres cuerpos, que, en total, no sobrepasa los $600 \mathrm{~m} 2$ (fig. 1), elevado el central y coronado por altas ventanas polilobuladas que iluminan la Sala. Más bajo, de dos plantas, y ocultando parcialmente las antedichas ventanas, se adosa el cuerpo Sur por el que se accede al recinto, y en cuya planta primera se encuentra la Galería de Mujeres (fig. 2). Al Norte se adosa el tercer cuerpo, de una sola planta, posiblemente del Siglo XVIII, donde se ubican las salas del actual 
Museo. El aspecto exterior de las fábricas es sucio y descompuesto, debido a la agresión meteorológica y a la polución, sobre todo en el testero Oeste por soportar la calle de los Reyes Católicos un intenso tráfico (fig. 3 ).

Sobre la vertical del portalón de acceso, en el cuerpo Sur, sobresale de la cubierta una espadaña que manifiesta el pasado uso católico del edificio. Ésta se adosa a una construcción de pobre calidad y extraña configuración, cuyo entendimiento resulta difícil. Esta construcción, cerrada y con cubierta a un agua que vierte sobre la trasera de la espadaña, oculta dos de las ventanas perimetrales de la Sala, rompiendo el ritmo de su iluminación. El arriostramiento de la espadaña se realiza mediante grandes vigas de madera que se reciben, precisamente, contra las ventanas ocultadas (véase más adelante fig.19).

Sorprende en este cuerpo de acceso, tanto en su frente Sur como en la vuelta al Oeste, la proliferación de ventanas, pequeñas o medianas, aparecidas al socaire de los múltiples usos a los que se dedicó, particularmente, en la época en que la Galería de Mujeres, situada en planta primera, fue vivienda del capellán. Entre todos los huecos existentes destaca, por su emblemática situación en la vertical del acceso, una ventana ajimezada realizada en la restauración de 1969 (fig. 4).

\section{Interior}

Traspasado el umbral, el visitante entra en un minúsculo vestíbulo donde obtiene su entrada a través de un ventanuco practicado en una de las paredes. En vitrinas, que poco invitan a la observación, se le muestran avisos, catálogos, etc (fig. 5). Tras este pequeño y pobre espacio sorprende aún más la magnificencia del que se visita a continuación:

La Sala de Oración es un prisma casi rectangular (el muro de poniente no es perpendicular a la generatriz) de $24,77 \mathrm{~m}$. de largo por 9,54 m. de ancho, y $12,85 \mathrm{~m}$. hasta la terminación superior de sus muros. Su eje longitudinal coincide casi exactamente con el Este-Oeste, situando el Hejal en el frente Este. Sus paredes arrancaban, posiblemente, con un zócalo de azulejería hoy perdido, y se rematan con un primer friso de yeserías mudéjares; un segundo, más alto, en el que se incluyen arcos polilobulados, ciegos o abiertos, que dotan a la Sala de una luz tenue y uniforme; y un tercero formado por una cinta con inscripciones hebraicas. El paño del Este, por contener el Hejal, derrama sus yeserías góticas y naturalistas hasta el nivel del zócalo inferior, uniéndose, en sus motivos, las tres culturas que intervinieron en su realización. Entre zócalo y friso se extiende un entelado de seda dorada, de reciente factura, que refuerza el tono de la iluminación del espacio (fig. 6).

La Sala se cubre con una armadura de perfecto trazado con lacería en madera policromada. Su sección es de forma de artesa, de unos 3,00 m. de alto, con las esquinas ochavadas y resuelta con cinco pares de tirantes que se apoyan sobre canes lobulados. El plano superior de la artesa se decora con lazos de ocho (fig. 7).

El paramento del lado Sur presenta, en su parte baja, un altar plateresco donde
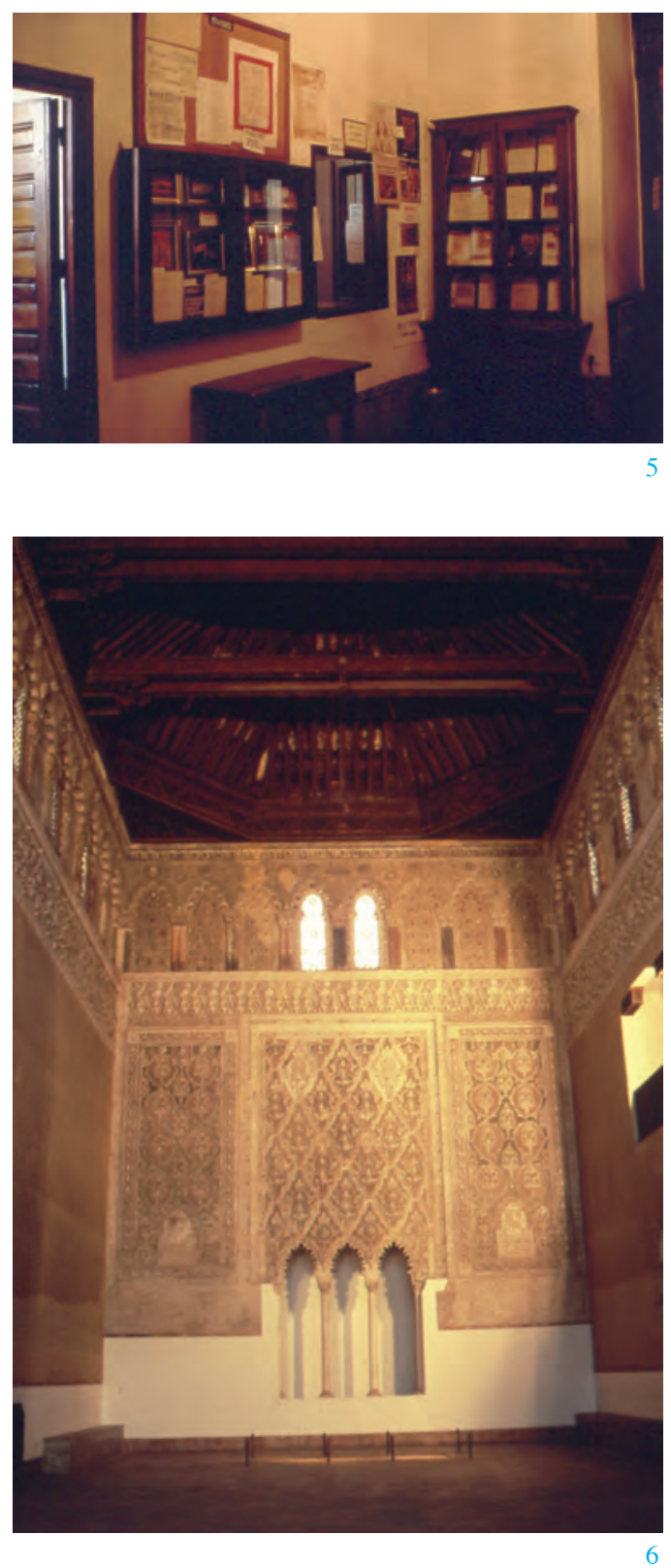

2. Fachada del acceso: el cuerpo central, la Sala de Oración, pierde el ritmo de iluminación de los huecos superiores por la existencia del campanario

3. Fachada Oeste: deterioro del paramento sobre la calle de los Reyes Católicos

4. Detalle del acceso: espadaña superpuesta al campanario, ventana ajimezada y otros huecos diversos

5. Vestíbulo público: taquilla y expositores

6. Sala de Oración: frente del Hejal 


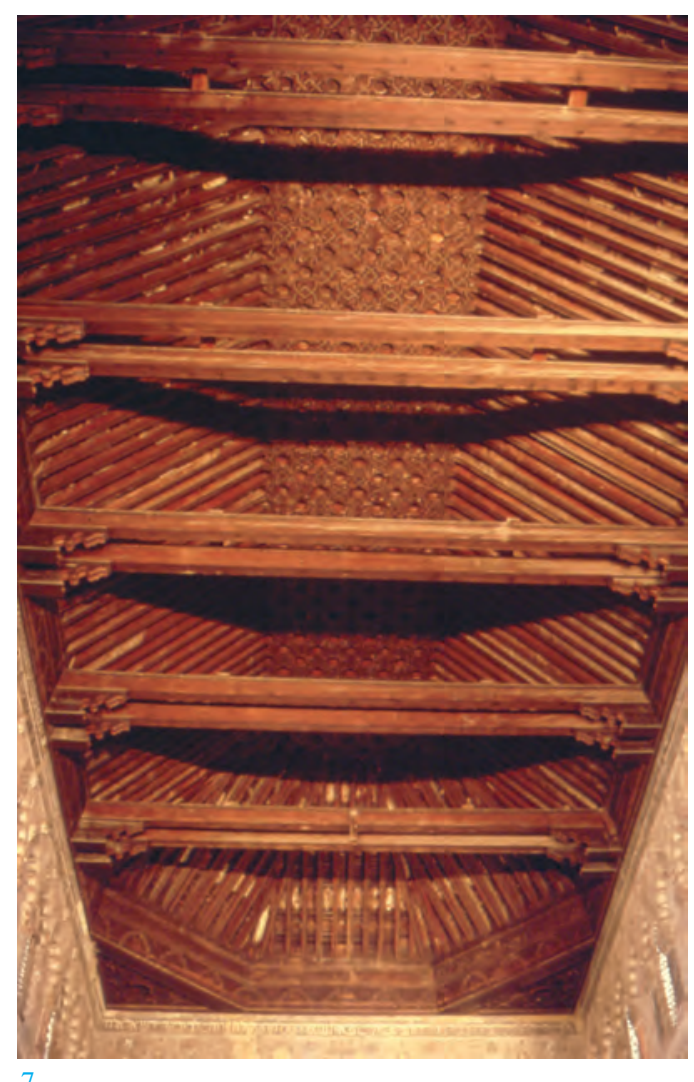

7

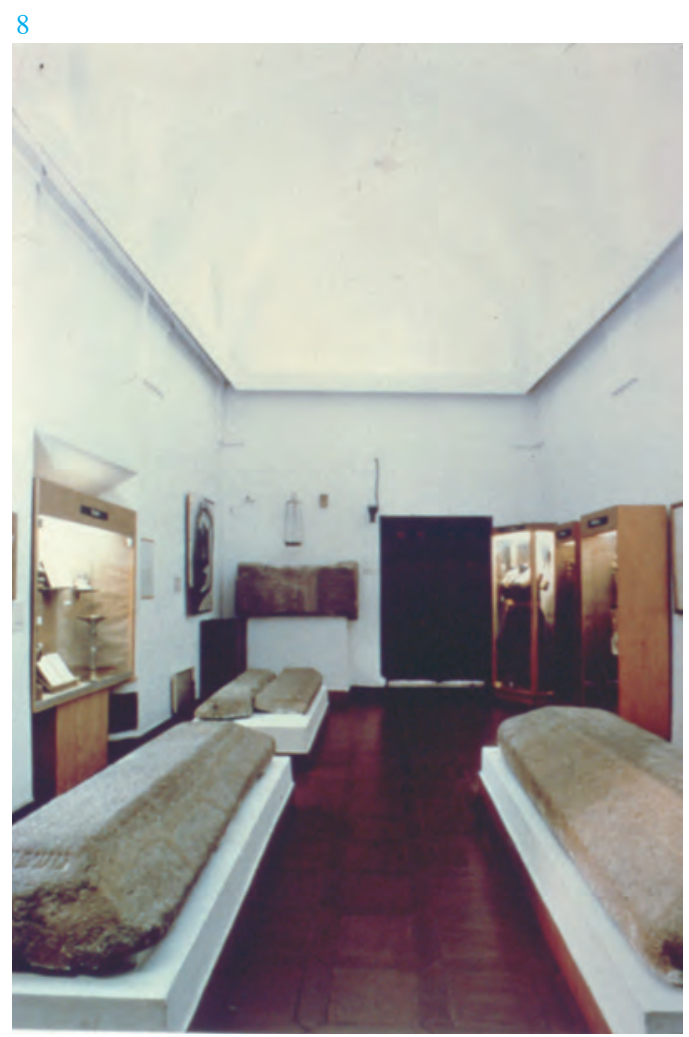

se encontraba el cuadro del Tránsito de La Virgen que dio nombre a la ermita. Junto a él, una portada, también plateresca, enmarca la puerta de conexión con la sacristía católica. Sobre este primer nivel de elementos aparecen los cinco grandes huecos de comunicación entre la sala de Oración y la Galería de Mujeres. En el borde Suroeste el friso situado por encima de estos huecos presenta una aparatosa grieta, quizá por empuje de la espadaña.

En el zócalo del frente del Hejal se aprecian humedades, de origen directo o por capilaridad del muro. Paramentos y artesa se presentan descoloridos y sucios ya que la gran altura de la Sala hace difícil la limpieza de unos y otra. El estado de conservación, en una primera observación, aparenta ser correcto aunque descuidado.

El paramento Norte de la Sala tan solo muestra un pequeño hueco de comunicación con el pabellón situado en ese costado, practicado por una puerta que presenta una bella cruz de la orden de Calatrava.

Atravesando ésta, se penetra en el pequeño cuerpo donde se ubican las únicas salas del Museo. Se trata de una construcción del S.XVIII, partida en tres estancias, rematada cada una de ellas con falsa bóveda. Los dos muros transversales que separan las salas, así como sus testeros de cierre al exterior, presentan grietas verticales, posiblemente por el empuje de las bóvedas o de la cubierta. Las puertas que las comunican son pequeñas. Las ventanas están desordenadas (sirvió este pabellón como vivienda del conserje de la Casa del Greco) y ocupadas por expositores. En espacio tan reducido, los objetos museables se agolpan en vitrinas adosadas a las paredes. Las laudas sepulcrales colocadas en el centro de las sala dificultan la circulación. Al fondo Este se abre una puerta que permite el acceso al patio trasero (fig. 8).

El visitante retrocede, contempla de nuevo la Sala de Oración, y vuelve al vestíbulo; ha terminado su recorrido. En ese mismo vestíbulo, frente a la taquilla, una puerta flanquea el acceso a la sala de trabajo del Museo Sefardí. Tras ésta, y en lo que fuera la antigua sacristía gótica con bóveda de terceletes, se sitúa el despacho de dirección. La comunicación con la Sala de Oración, de remarcado plateresco antes citado, ha sido convertida en armario. El nivel del suelo de ambas salas se encuentra por debajo del de la calle del Greco, lo que provoca humedades directas.

Tras la mesa de trabajo del despacho de dirección, una doble puerta comunica con la estrecha escalera de dos tiros que conduce a la Galería de Mujeres. Ésta ocupa la totalidad del cuerpo Sur, extendiéndose sobre vestíbulo, oficina y sacristía. Se presenta como un único espacio, más bien bajo, comunicado visualmente con la Sala de Oración a través de los cinco grandes huecos antes citados. De la cinta de yesería que remataba el espacio, sólo queda la que linda con la Sala y con la escalera. Perdido el color, algunos trozos se presentan muy oscurecidos por el humo de lo que fue cocina de la vivienda que aquí se instaló. El espacio, que se usa como almacén, está negado al público por su obligado acceso a través de la Dirección y por la flecha de su forjado que lo hace inutilizable. El techo, poblado de agujeros, permite la entrada de polvo y otros agentes agresivos (fig. 9). 
Desde el descansillo de esta escalera se sale al patio trasero que se encuentra unos dos metros por encima del nivel de la Sala de Oración. Este desnivel y la segura ausencia de un drenaje perimetral pueden ser los causantes de las humedades observadas. Adosado a todo lo largo del paramento de la Sala, se sitúa un estrecho porche que en su centro techa el armario del Hejal, y en su extremo protege la puerta de comunicación con el cuerpo Norte, donde se encuentran las salas del Museo. Patio residual, existe en una de sus esquinas una pequeñísima construcción que contiene los únicos servicios y aseos, tanto para uso del público visitante como de los funcionarios, de que dispone el edificio.

\section{Jardín}

De nuevo en el exterior, y adyacente al cuerpo Norte, nos encontramos con un ambiguo y abandonado jardín. Su orientación provoca que las hiedras forren incontroladamente la fachada del museo. Ambiguo porque, aunque abierto a la calle y con acceso directo desde las salas del museo, se encuentra delimitado por una reja (la del Cristo de la Luz, trasladada, posiblemente, por el Marqués de la Vega Inclán) haciendo dudar si de jardín público o privado de trata. Investigaciones posteriores aclararon que éste pertenecía al Museo Sefardí.

En la plazuela que dicho jardín genera en el tejido urbano, se construyó hacia 1.969-70, a modo de casa solariega toledana, una edificación de dos plantas. Cedida recientemente al Museo, se usa como sala de conferencias, biblioteca y otras actividades propias del mismo, a pesar de no existir conexión física entre uno y otro.

\section{ANÁLISIS Y OBJETIVOS}

En el reconocimiento descrito habíamos encontrado lo que era de esperar en un edificio con más de 600 años. Por un lado, aparecían las normales patologías de la vejez constructiva: goteras, humedades en muros, flechas en forjados, grietas estructurales, etc. Otras, tales como la existencia generalizada de xilófagos, necesidad de excavaciones arqueológicas, o escasa fijación de yeserías con su consiguiente peligro de desprendimiento, no pudieron observarse en la inspección visual realizada. Aparecieron, y debieron ser acometidas, a lo largo de las obras proyectadas.

Por otra parte, los diversos usos soportados necesitaron de adecuaciones que, poco a poco, fueron modificando la imagen y la estructura original. En lo que pudimos comprobar después, la mayor parte de las actuaciones tan sólo supusieron, afortunadamente, alteraciones que pudieron ser reversibles. Sin embargo, el uso dado a la Galería de Mujeres produjo la pérdida irrecuperable de parte de sus yeserías.

En el aspecto funcional observamos el precario espacio museográfico, las incorrectas circulaciones y usos de algunos de los espacios disponibles, así como el total desuso de otros. Igualmente, se aprecia la obsolescencia de ciertas instalaciones y la total carencia de otras necesarias para un museo.
7. Artesonado, donde se aprecian piezas desprendidas que provocan cambios de coloración

8. Sala del Museo: expositores sobre paramentos o dentro de los huecos de las ventanas. Las laudas, en el suelo, dificultan la circulación

9. La Galería de Mujeres ocupada por vitrinas y arcones que se forran con papeles para protegerlas de las agresiones externas

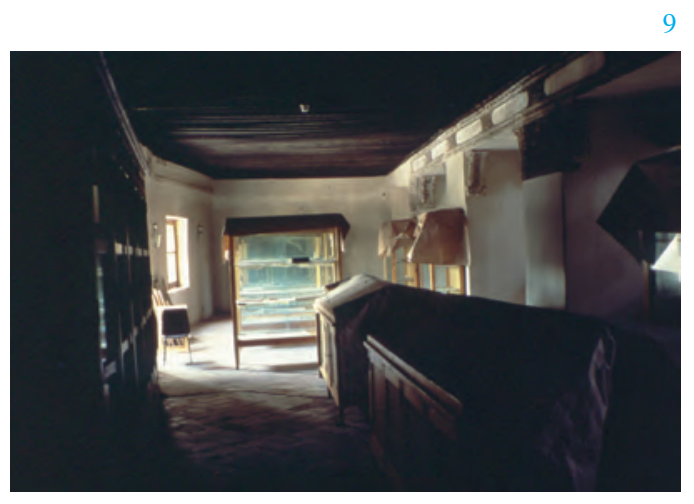


10. La fachada de la Sinagoga según el grabado de Palomares de 1753. Refleja con claridad la primitiva construcción sobre la que posteriormente se adosó la espadaña actual
Desde este primer reconocimiento se nos presentaron de inmediato algunos objetivos por conseguir. Sin lugar a dudas, el primero, claro y contundente, es el de convertir a la propia Sinagoga en la mejor pieza expositiva del Museo Sefardí. En innumerables ocasiones se recurre a los edificios históricos para albergar museos, pero pocas veces habría estado tan claro que el continente superase al contenido, no por el menor valor de éste, sino por el enorme de aquél. Planteado el edificio como un objeto de museo, es preciso recuperar para el visitante los espacios que hasta ahora le son negados y sin los cuales resulta incompleta la comprensión del mismo (Sacristía, Galería de mujeres, etc). No menos importante resulta devolver a la Sala de Oración la continuidad de su alta iluminación perimetral, cortada por la construcción que soporta la espadaña y que había provocado, además de una aparatosa grieta en las yeserías, la pérdida de la nítida volumetría exterior del cuerpo central. Convencidos de que en este caso la decoración es un elemento inherente a la definición del espacio, resulta obligatorio la limpieza y restauración de telas, yeserías y artesonado.

Puesto que de museo se trata, es imprescindible, tanto para su funcionamiento, como para conseguir la recuperación antedicha, proceder a una redefinición de espacios, usos, y circulaciones. Desplazar Administración y Dirección al edificio anexo permitiría ampliar el vestíbulo, liberar la Sacristía y acceder a la Galería de Mujeres. Las salas del museo, en fondo de saco, requieren de una circulación alternativa, aunque ello pueda suponer una agresión física. También es necesario el aumento de su angosto espacio expositivo, incorporando el patio y el jardín a tal uso. Hay que dotar al conjunto de una infraestructura con capacidad suficiente. Electricidad, seguridad, comunicaciones, etc., escasas o casi inexistentes, deben plantearse con cierta perspectiva.

Corregir los deterioros constructivos encontrados, aunque amplios en número, sólo requieren intervenciones razonables que no tienen por qué ser traumáticas para el edificio.

\section{ESTUDIO HISTÓRICO}

10

El diagnóstico estaba hecho. Las intervenciones necesarias, más o menos claras y decididas. Faltaba el conocimiento histórico del edificio. No para reconstruirlo o devolverlo, cual máquina del tiempo, a un momento de su historia, sino para comprender mejor su estructura. Una análisis de cualquier edificio, a través de sus parámetros arquitectónicos y constructivos, debería ser suficiente para la comprensión del mismo. Recurrir a documentaciones históricas, gráficas o escritas, aportó en este caso concreto, explicaciones y conocimientos en el tiempo. Era preciso saber discernir entre las partes y elementos que pertenecían a la estructura original, y las que eran añadidos, alteraciones o modificaciones. Conscientes de que nuestra intervención también supondría nuevas alteraciones, necesitábamos poder valorar éstas a fin de aceptarlas o rechazarlas.

Cronológicamente, la documentación más antigua encontrada son los gra- 
bados de Palomares, fechados en 1.753. Uno de ellos refleja la fachada de acceso. El otro dibuja la planta del conjunto, la de la Galería de Mujeres, y la sección longitudinal de la Sala de Oración.

El de la fachada presenta huecos, recercados y otros elementos hoy desaparecidos. Sobre la vertical de la puerta de acceso aparece dibujado el pobre cobertizo que hoy subsiste, con dos huecos adintelados y otros dos con arco, que resulta ser un campanario. Forma y composición exactamente igual a la actual, pero sin espadaña. Tal parece que ésta se hubiera adosado simplemente a la construcción preexistente, cegándola parcialmente (fig. 10).

El dibujo de la planta y sección refleja que la estructura geométrica ha permanecido prácticamente inalterada. Existen, sin embargo, algunas diferencias importantes. En el lugar del Hejal aparece un altar, y en el paramento opuesto, el del Oeste, se representa un coro sustentado por un pilar central. El grabado de Quadrado y Vidal, de 1.886, lo refleja y Amador de los Ríos lo describe en 1.905, poco antes de que fuera demolido, con la obligada discusión sobre si este coro era pieza original o añadida posteriormente. La escalera de acceso a éste, desde el vestíbulo, ha desaparecido igualmente.

Los cinco grandes huecos de la Galería de Mujeres sobre la Sala de Oración se dibujan cegados. El grabado de Villaamil, del siglo XIX, representa el frente del altar, con el retablo barroco que ocultaba el Hejal, y parte del lado derecho con la portada de la Sacristía y el altar del Tránsito sobre un lienzo ciego (fig. 11). Esto explica el extraño remate del altar contra uno de esos huecos, tras la apertura de éstos. La escalera de subida a la Galería se sitúa en el mismo lugar donde hoy se encuentra, pero con traza diferente y con acceso directo desde el exterior.

Otros pequeños elementos, altares, fuentes, etc. han desaparecido también. Planta y sección de Palomares indicaban la existencia de un altar con arcosolio, dedicado al Cristo de los Remedios, en el muro de separación entre la Sala y el cuerpo Norte. Dato éste que propició, tras comprobar su existencia, la única intervención que se realizó en la Sala de Oración.

Las fotografías más antiguas encontradas datan de principios de este siglo, cuando Isidori estaba realizando la restauración tras ser declarada la Sinagoga como Monumento Nacional, o con ligera posterioridad a esta fecha. Es ahí cuando aparece por primera vez la greco-romana espadaña, en palabras de Amador de los Ríos, que, como indicamos en un punto anterior, se adosa llanamente al campanario. En una de ellas, del interior, aparece el Hejal dotado de una vidriera trasera. En la otra, del exterior, se muestra, andamio incluido, la apertura de los tres huecos cuadrados de la fachada Oeste que hoy se encuentran protegidos con unas celosías de madera. Salvo detalles, unas y otras fotografías reflejan una situación que en poco se diferencia de la actual. Tan sólo hay dos modificaciones que se realizaron en 1.970. Por un lado, y con buen sentido, se cegó la vidriera tras el Hejal. Por otra parte, creemos que no con tan afortunado criterio, se abrió una ventana ajimezada con parteluz sobre la puerta de acceso.

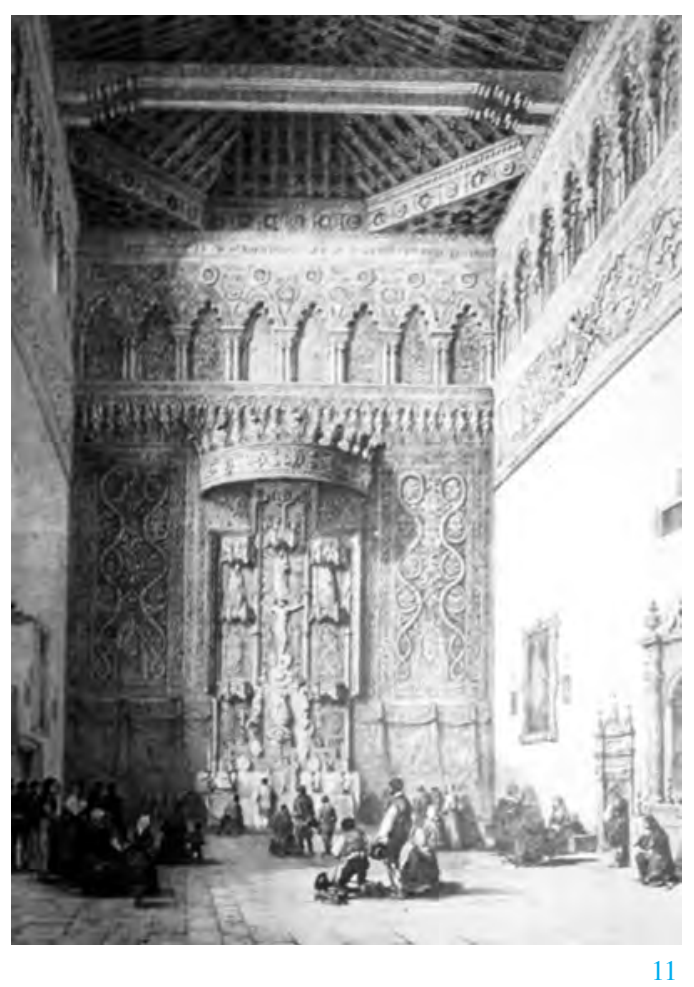

11. El grabado de Villaamil, del s.XIX, muestra el retablo barroco que se desmontó hacia 1905. El paramento Sur presenta tapiados los huecos de la Galería de Mujeres. En el opuesto aparece el arcosolio indicado en los planos de Palomares y Czekelius 
12. Planta Baja del conjunto tras la intervención. Museo y pabellón administrativo conectados. Vestíbulo de acceso, patio y jardín con su nueva configuración

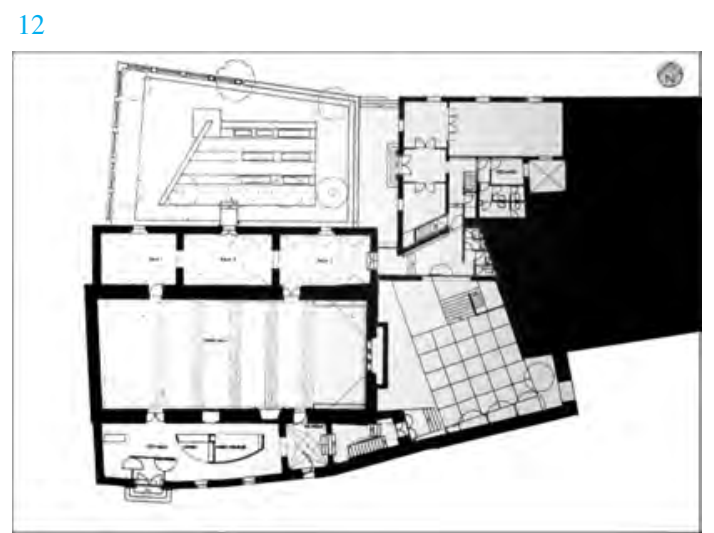

\section{CRITERIOS PARA LA INTERVENCIÓN}

Habíamos recorrido el edificio, acercado a la comprensión de su cultura, observadas las patologías, y conocida su historia, con las lógicas lagunas por su dilatada vida. Llegaba, ineludiblemente, el momento de sentar las bases para la intervención.

Todo este proceso de análisis, coincidente en cronología y método, sirvió, como insinuamos anteriormente, para confirmar alguna de las primeras decisiones intuidas, y matizar o rechazar otras. Se aclararon algunas dudas de carácter arquitectónico, pero no todas.

Una de ellas se refiere al tratamiento de la luz en la Sala de Oración. La voluntad de una iluminación continua y perimetral estaba clara. Sin embargo, como ya señalamos, el faldón de la cubierta del cuerpo Sur acomete, más o menos, a la mitad de la altura de éstas, reduciendo la superficie de iluminación y provocando la entrada de agua. Podría pensarse que el arranque de dicho faldón no es el adecuado, pero su coincidencia con el nivel de la cinta de yeserías de la Galería de Mujeres lo confirma. Diferente traza de la cubierta, construcción de la Galería con posterioridad a la Sala, o simple defecto constructivo original, es una duda que se mantiene.

Todas las ventanas polilobuladas poseen una celosía que tamiza el nivel de iluminación haciéndolo intencionadamente suave. Por ello, tenemos dudas de que los tres grandes huecos que abre Isidori en el paramento Oeste fueran realmente ventanas, ya que el nivel de iluminación que aportan no es coherente con el de los restantes. Tal es así que pronto se tamizaron con celosías de madera por el exterior.

Con todo, comprendido o no, el edificio llegado hasta nosotros era el que era, con lo añadido o lo suprimido, que tanto lo uno como lo otro narraban su historia. Había que escribir otra página.

Cuando de intervención en edificio histórico se trata, y ése es el criterio planteado, el protagonismo debe continuar en el edificio, no en lo que se aporte por necesidad de esa intervención. Alejandro de la Sota afirmaba que "un diente de oro, por mucho material noble que sea, siempre afea una boca". El mimetismo, por simple ambigüedad unificadora, es rechazado al igual que se renuncia a recuperar elementos perdidos $u$ otros que, aunque aparentemente lógicos, no están suficientemente documentados (ventanas y coro en paño Oeste). Desde el punto de la restauración estructural, entendemos que nuestro trabajo consistirá en limpiar sosegada y tranquilamente todos los aditamentos que perjudiquen la lectura del edificio. La aportación formal que necesariamente habrá que realizar deberá supeditarse a esa clara lectura, aunque sin negar, en cultura y lenguaje, el momento de la historia en que se produce. Por otro lado, las intervenciones que se deben efectuar serán proporcionalmente inversas al valor del espacio intervenido. Mínimas en la Sala de Oración (tan solo mera limpieza y estricta restauración), gradualmente menos condicionadas en el resto.

Conscientes de que esas intervenciones serían de muy diverso grado, amplias en unas ocasiones, puntuales en otras, y afectas a espacios de distinta época y 

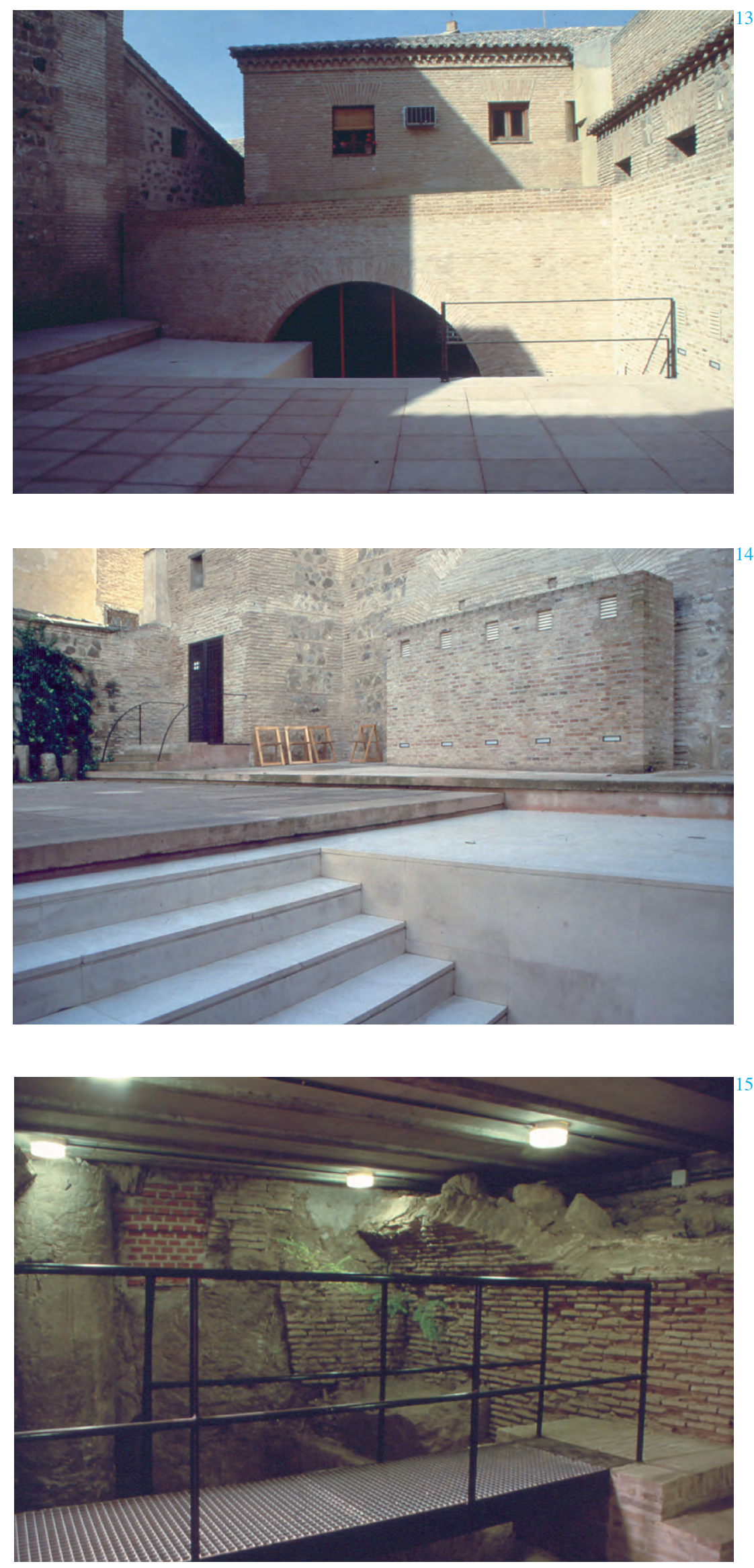

13. La conexión entre Museo y oficinas desde el patio trasero mantiene la separada volumetría de los edificios. El arco supone una forma neutra de acceso

14. Las plataformas de piedra y hormigón envuelven los diversos elementos del patio trasero y configuran la geometría

15. Pasarela para el recorrido entre las excavaciones arqueológicas 


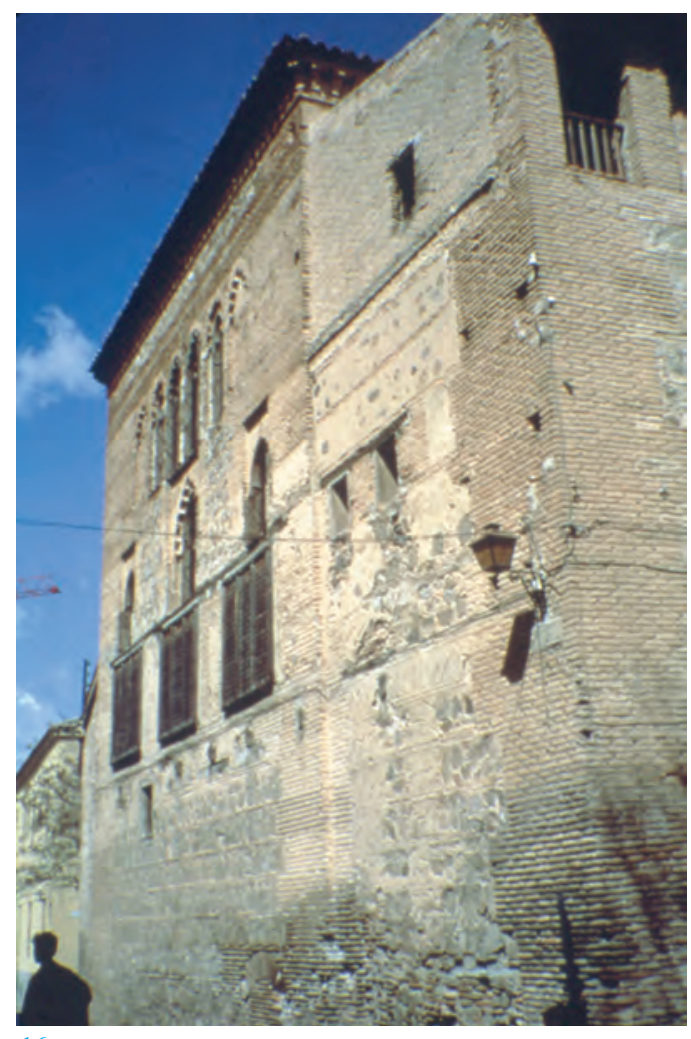

16

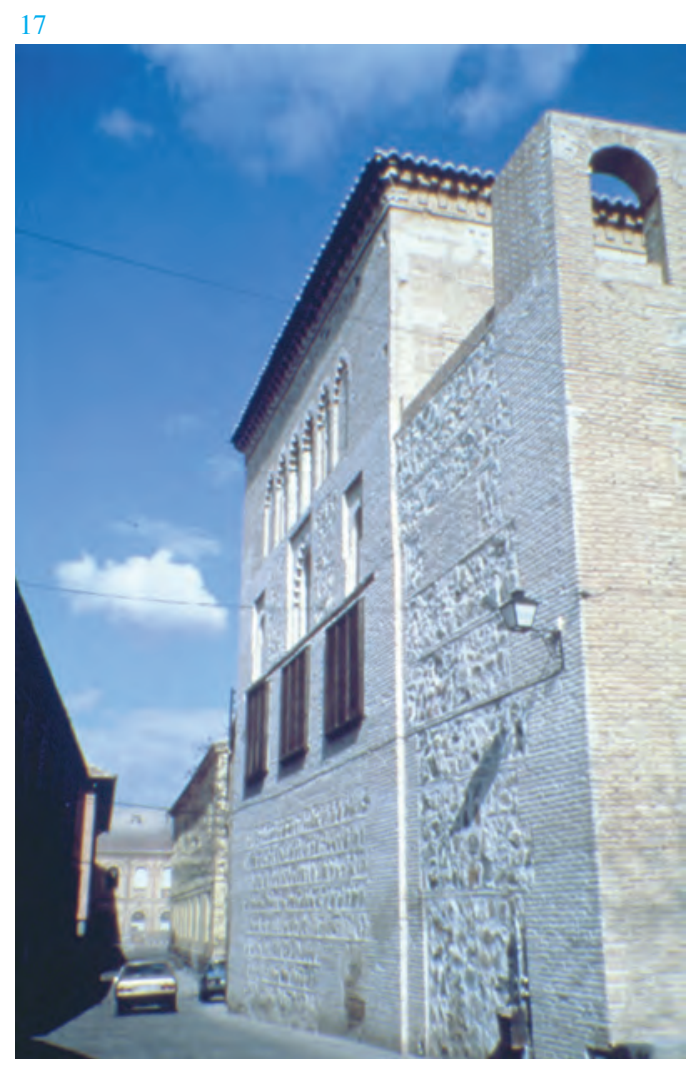

valor, resulta necesario introducir un lenguaje homogéneo que dé continuidad al conjunto de las operaciones. En tal sentido, dedicamos especial atención a los nuevos materiales que serían pocos, pero adecuados en función e imagen. Su elección dentro de la gama de los presumiblemente originales ayudará a la integración entre lo existente y lo añadido. Suelos y zócalos deben ser capaces de soportar un uso intenso. Arcilla cocida a altas temperaturas con encintados y zócalos de piedra caliza, cumplen con estos requisitos. Escalera y forjados interiores mantendrán su construcción en madera. Para las nuevas carpinterías, empanelados y suelos sólo se utilizará el haya, por color acorde con el dominante y por su manifestación respecto a las otras maderas existentes. Las piezas nuevas se plantean, con criterio de reversibilidad, a modo de muebles o forros adosados, al objeto de que por forma y materiales nunca equivoquen en cuanto a la época de su realización.

Las nuevas instalaciones de seguridad, emergencias, detectores de humos, etc, son necesarias y no pueden ser negadas. Deberíamos conseguir una colocación eficaz, pero discreta. Objetivo realmente difícil a veces ya que, como es obvio, las normativas que rigen sobre éstas no están previstas para casos como el que nos ocupa.

Hasta aquí las premisas y los criterios. Ahora la respuesta, cuando se produce la ruptura del proceso racional. Es decir, el inexplicable salto en el vacío que da paso a las soluciones arquitectónicas.

\section{LA INTERVENCIÓN}

La Sinagoga del Tránsito es uno de los Monumentos más visitados de Toledo. Recibe entre 250.000 y 300.000 visitantes al año. Por ese motivo, se estableció un plan de obras que permitiera mantenerla abierta el mayor tiempo posible, aunque alguna de sus dependencias no se visitaran temporalmente. Se estableció un orden de intervenciones que tan sólo cerraba la Sala en la última etapa de las obras. Vano esfuerzo de programación, porque los imponderables arqueológicos que aparecieron echaron al traste el orden prefijado. Más o menos acorde a ese plan, describiremos las obras que se ejecutaron (fig. 12).

\section{Pabellón de Oficinas y Patio trasero}

Concentrar los servicios administrativos del museo, ahora dispersos, parecía lógico. Pero, además, era condición previa y obligatoria para remodelar el cuerpo de acceso y recuperar la Galería de Mujeres.

Carente el edificio anexo de valor arquitectónico, tan sólo se realizaron en él pequeñas operaciones de carácter funcional. Una ligera remodelación permitió dotarle de sala de conferencias, biblioteca, despachos, sala de control de instalaciones y de seguridad, aseos y vestuarios de personal, laboratorio de apoyo y un almacén.

Crear una conexión entre la Sinagoga y el edificio de administración y oficinas era indispensable para un correcto funcionamiento del conjunto. Para ello se proyectó, ocupando un lateral del patio trasero, un vestíbulo que articula las oficinas, el museo y el resto del patio trasero. Una salida directa hacia 
éste permitirá su uso y el acceso, por el exterior, a la Galería de Mujeres. Todo ello obliga a una nueva configuración del patio para lo que resulta necesaria la demolición de los antiguos aseos, que para el público se sitúan en el nuevo vestíbulo, y la del porche que se adosa al muro de la Sinagoga.

El vestíbulo se proyecta intencionadamente de poca altura, de tal manera que no se pierde la volumetría de la Sinagoga ni la separación, siempre existente, entre ésta y las oficinas. El cierre de este vestíbulo se presenta, desde el patio, como un muro de ladrillo perforado por un falso arco, que se dobla sobre las medianerías colindantes al objeto de unificar las texturas de las medianerías del perímetro (fig. 13). Los múltiples niveles que confluyen en el patio (escalera a la Galería, el nuevo vestíbulo, e incluso el del propio patio) así como la quebrada geometría de los elementos que lo rodean, pretenden ordenarse con un trazado central ortogonal de baldosas de hormigón coloreado y planos laterales, del mismo material, que salvan los desniveles y envuelven todas esas formas (fig. 14).

Bajo uno de estos planos se sitúa el tendido de la infraestructura de instalaciones que, centralizada en el edificio de servicios, se distribuye por el patio y, en estructura de peine, penetra en los cuerpos adyacentes a la Sala de Oración. La aparición bajo el patio de unos antiguos aljibes y de los posibles restos de un baño ritual judío supuso un quebranto en el orden de la obra. La extensión de la excavación arquelógica hasta el mismo muro de la Sinagoga permitió descubrir la traza del antiguo Hejal. Quedó comprobado que no se trataba de un armario, tal como se nos presenta a lo largo de este siglo, sino de una habitación que, posiblemente, formaba parte de un conjunto más amplio de estancias. Tras decidir mostrar los restos encontrados, fue necesario modificar la solución constructiva del patio a fin de hacer visitable la excavación realizada. Sobre los muros de las estructuras aparecidas se construyen vigas de atado en las que se apoya un forjado (fig. 15). Cubierta invertida y solado flotante, de color y textura como la prevista, reajustan el diseño inicial. La escalera que conecta patio y vestíbulo se modifica introduciendo un nuevo tiro que desciende a las excavaciones.

\section{El cuerpo de acceso}

El campanario, aunque del siglo XVIII o anterior, es una pobre construcción de mala calidad. Su cubierta, a un agua y pendiente hacia el exterior, tapa dos de las ventanas superiores de la Sala y modifica la visión de la parte alta de ésta como elemento exento (fig. 16). La espadaña se adosó al campanario existente, sin modificar su geometría y volumen. Como arriostramiento de uno y otra, dos grandes vigas de madera se incrustan y reciben, precisamente, en las ventanas de la Sala (fig. 18). Recuperar el ritmo de iluminación, la imagen de la esquina Suroeste y corregir tan deficiente construcción es importante.

Para ello había tres posibles actuaciones: suprimir todo lo añadido y recuperar el volumen inicial del cuerpo de acceso; eliminar el campanario, por su mala construcción, manteniendo la espadaña como expresión del uso católico que tuvo en su tiempo; mantener ambas, por la imagen asentada, pero saneando
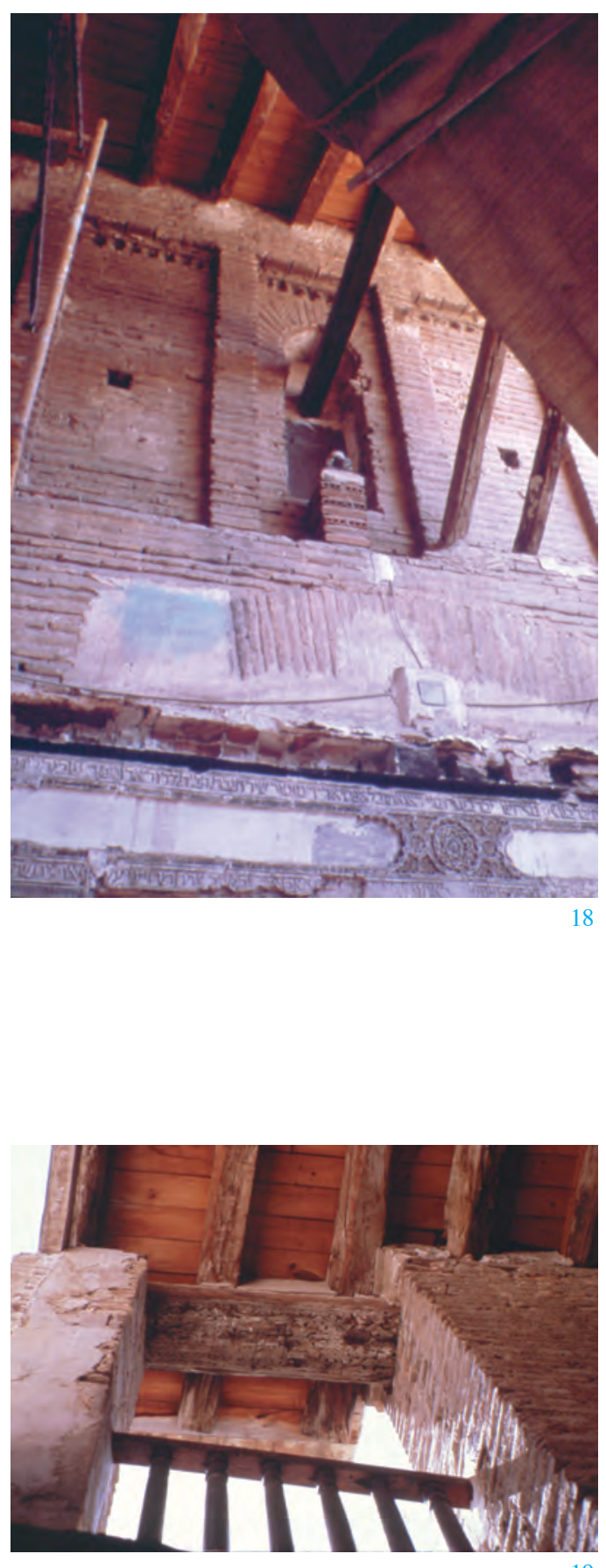

16. El testero del campanario, de pobre construcción, acomete contra el cuerpo central de la Sala desvirtuando la volumetría de ésta

17. Reestructurado el campanario, y sujetada la espadaña, el cuerpo central de la Sinagoga vuelve a mostrar su volumetría original

18. Puntales de arriostramiento de la espadaña contra el remate de las altas ventanas de la Sala

19. Viga mudéjar usada como dintel de uno de los huecos del campanario 


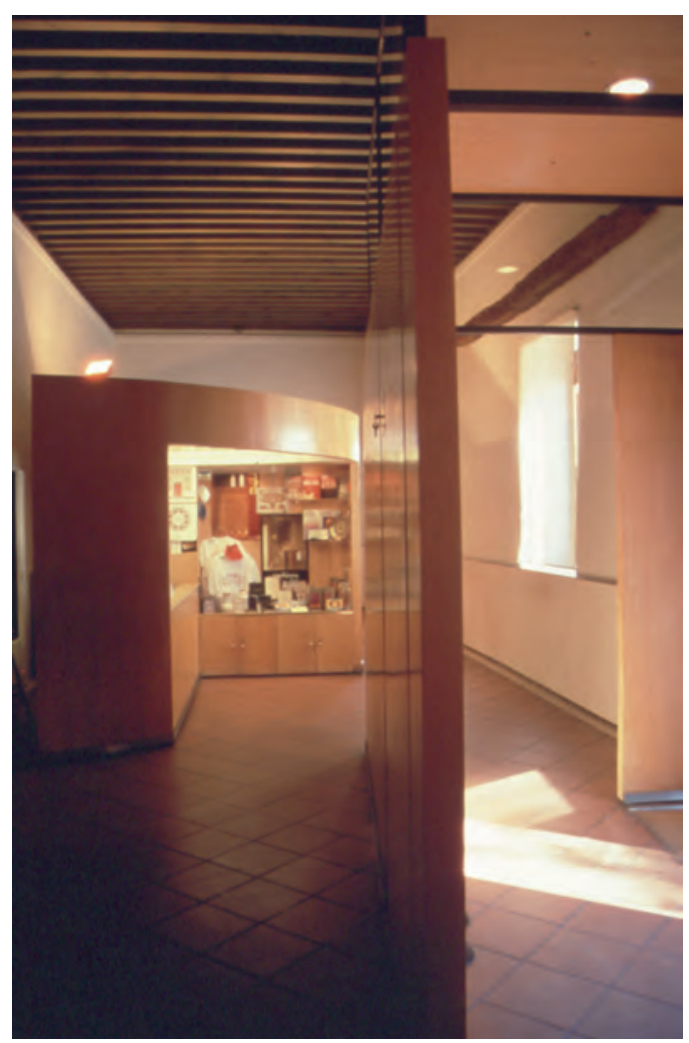

22

23

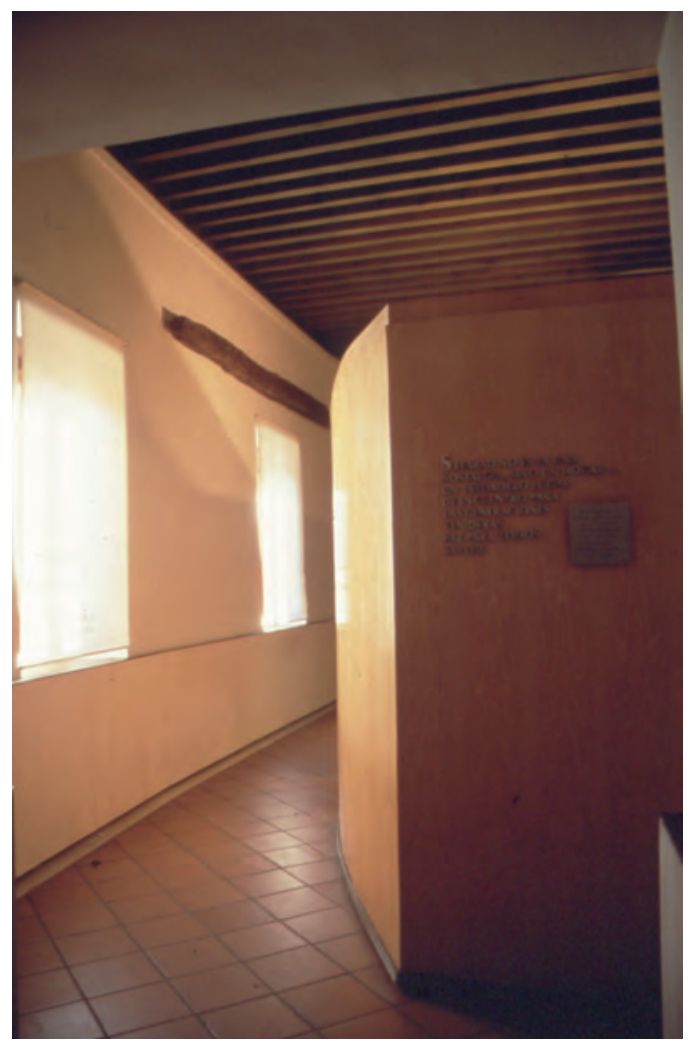

20. La fachada Oeste, sobre la calle de los Reyes Católicos, tras su restauración

21. Fachada del acceso. Volumen de la Sala de Oración liberado

22. El nuevo espacio del vestíbulo de acceso con el cortavientos, la tienda, y el techo

23. La forma del mueble-tienda canaliza la circulación de salida

24. La escalera a la Galería de Mujeres se define con el mismo lenguaje que las piezas del vestíbulo

25. La forma curva del trazado suaviza la acometida hacia la puerta original de acceso a la Galería de Mujeres
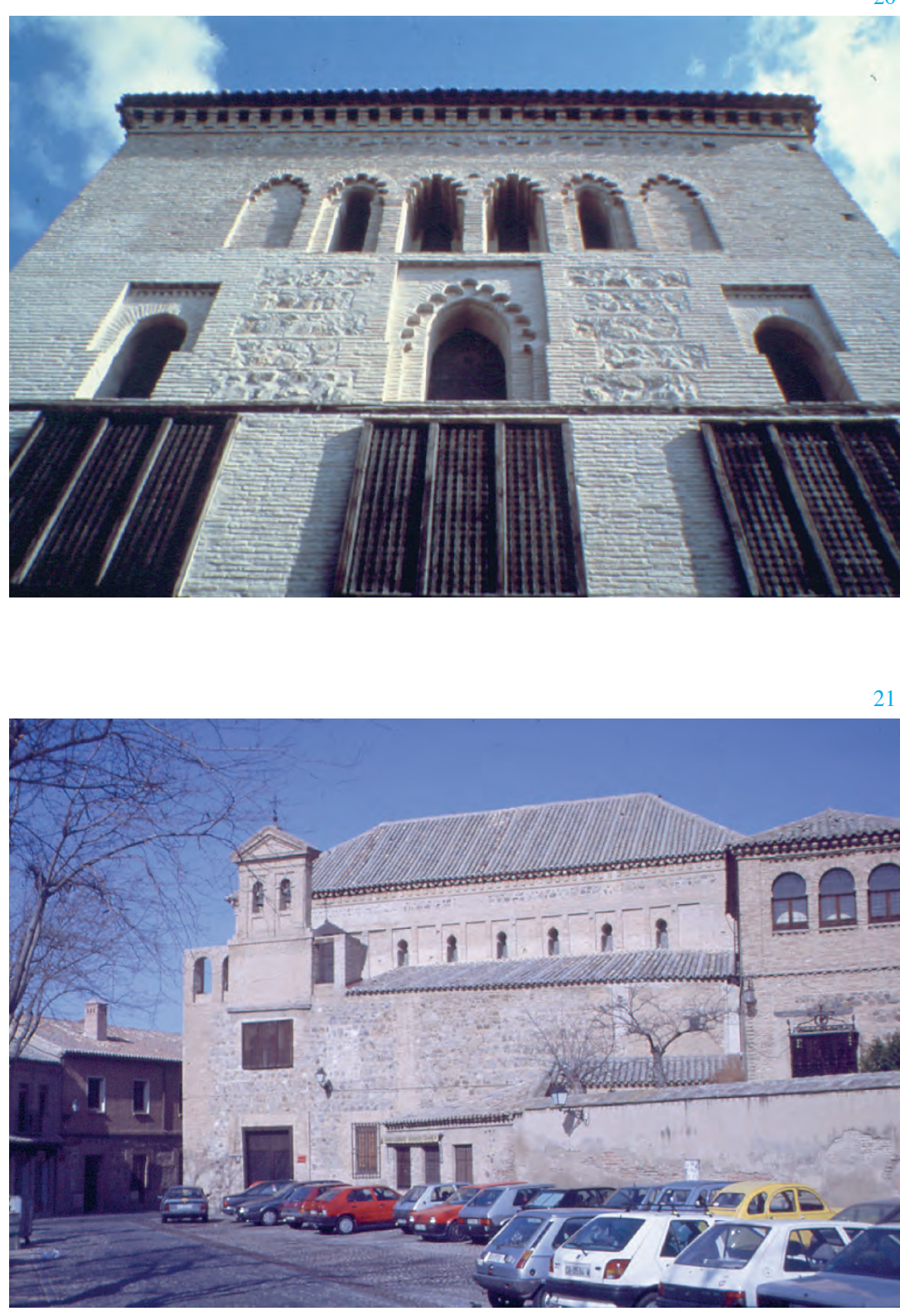
tan deficiente construcción.

La primera suponía la desaparición de testimonios de la historia, y no había seguridad de que al extender el faldón actual recuperara la forma original, por la duda, antes expresada, respecto a la ocultación parcial que su trazado provoca en las ventanas de ese costado. La segunda, por su parte, plantearía un problema de estabilidad de la espadaña al suprimir el cuerpo al que está unida. Optamos por la tercera vía por parecernos que alteraba menos la imagen, manteniendo las dos intervenciones de la historia. Se suprime la cubierta que oculta las ventanas y la espadaña se atarriostra al muro de la Sala mediante una estructura metálica empotrada. Del campanario se reconstruye su frente de $\operatorname{arcos}$ y dinteles, doblando las esquinas para recomponer el volumen y obtener mayor estabilidad, pero sin entestar contra el cuerpo central de la Sinagoga (fig. 17). Uno de los dinteles resultó ser una viga mudéjar reutilizada y que, una vez restaurada, es hoy es uno de los elementos expuestos en el Museo (fig. 19). Este frente se corona con una viga de hormigón coloreado que lo ata con la espadaña.

Las fachadas, sucias y decompuestas sus fábricas, se limpian, rejuntan o reconstruyen según la conveniencia de una u otra actuación (fig. 20). Los desordenados ventanucos, practicados para los antiguos usos, se cierran (fig. 21).

Estudiadas las plantas dibujadas por Palomares y Czekelius, apostamos por que el actual conjunto de taquilla, vestíbulo y sala de trabajado había constituido anteriormente un único espacio. Demolidos los tabiques, la traza de paramentos y composición del forjado superior, confirmaron la hipótesis. La viguería de éste se pretendía reutilizar, pero en su desmontaje se descubrió la existencia de xilófagos. Ello obligó a un tratamiento generalizado mediante vaporizaciones, inyecciones, e incluso la creación de una barrera perimetral al edificio. Ante la imposibilidad de reutilización de la madera, se opta por una construcción similar a la existente, pero con materiales y tratamientos actualizados, a base de nueva viguería de madera con sección adecuada a la nueva carga de uso. Como capa superior de reparto se fija a la viguería una doble familia contrapeada de tableros laminados. Al objeto de evitar un aspecto mimético, el conjunto de la madera se tiñe con anilinas verdes.

Definido el espacio como único, se necesitaba introducir diversos elementos que resolvieran el programa solicitado para el vestíbulo. Tales eran un cortavientos que orientara la entrada y la salida de público, mostrador para la obtención del billete, una tienda y un pequeño espacio para audiovisuales (fig. 22). Todos estos elementos se proyectan como piezas sueltas, con su propio techo si es que lo requieren, de tal forma que siempre pueda percibirse visualmente el espacio originario. Tienda y audiovisuales se configuran como un gran mueble cuya forma curva no sólo es expresión de la independencia de éste respecto del espacio, sino que sugiere las circulaciones (fig. 23). Al objeto de remarcar esa intención de independencia de las piezas, todas se diseñan como planos de madera de haya, rectos o curvos, barnizados en su color. El suelo, como ya dijimos, se acaba con baldosas de ferrogrés con encintado y zócalo perimetral de piedra caliza.
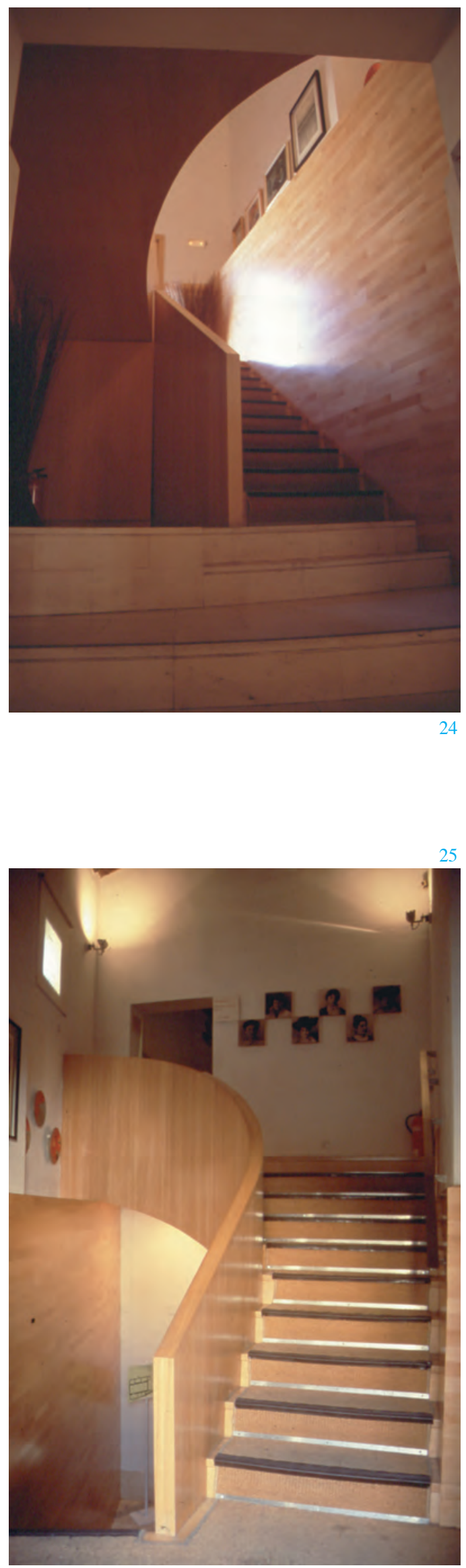


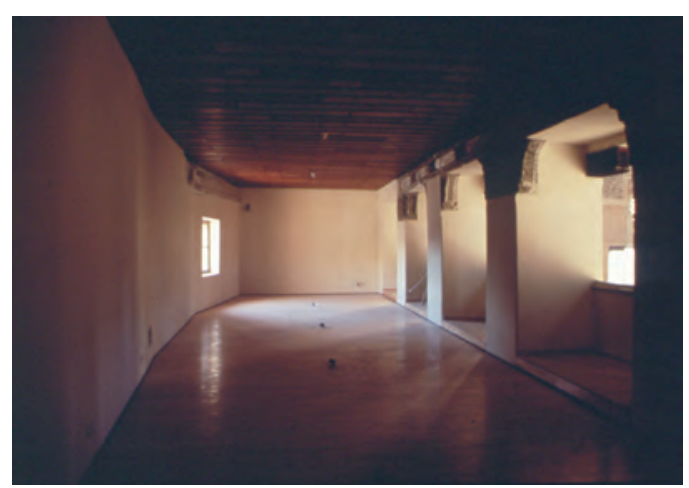

26

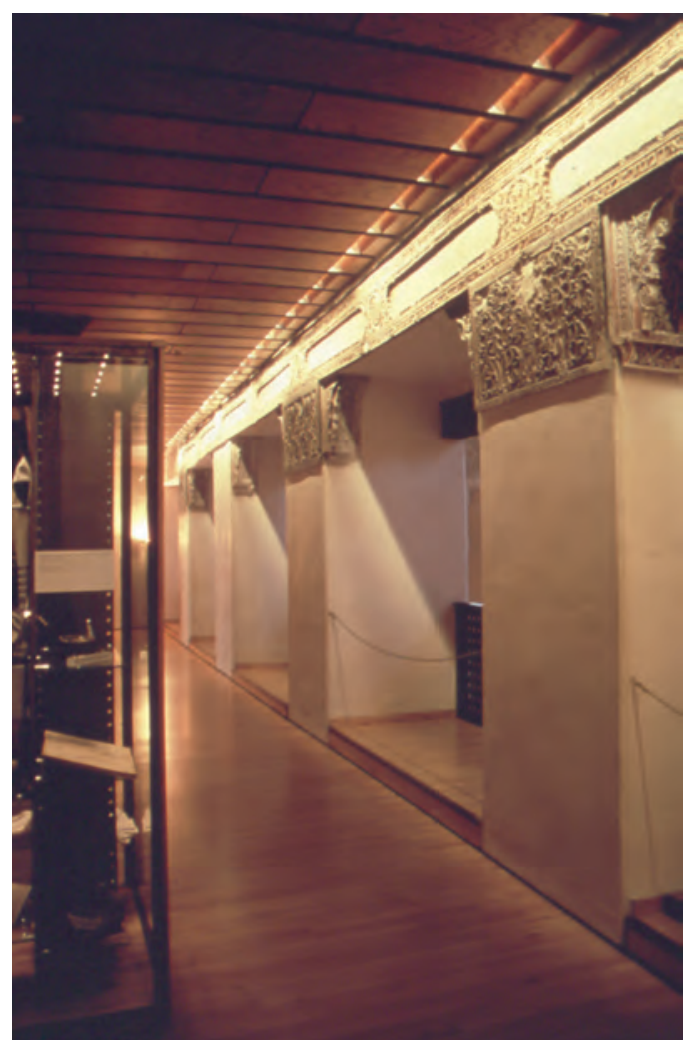

27
El siguiente espacio en este cuerpo de acceso es la Sacristía donde se encontraba el despacho de dirección. La labor radicó en centrar en su paño el hueco de acometida a la escalera (apoyándonos en el plano de Czekelius), solado y zócalo y restauración de paramentos.

La escalera de subida a la Galería de Mujeres resulta un punto de estrangulamiento circulatorio irresoluble ya que la subida y bajada de visitantes debe realizarse por la misma vía. La existente, que no es la dibujada por Palomares, es absolutamente doméstica en forma y trazado, y posiblemente realizada para la vivienda del capellán. Facilitar el recorrido, que no la imposible ampliación, y embocar correctamente sus acometidas, es el objetivo del nuevo trazado. La situación de la puerta de acceso a la Galería, adyacente al muro de fachada, es inamovible por tener, en su parte interior, un recercado de yeserías que manifiesta su primitiva situación. Esta posición, contraria a la normal con respecto al trazado de los tiros, es la que motiva la apertura en arco del segundo tiro. Construido con zancas y armazón de madera, petos y zócalos, se termina con entarimado de madera de haya. Una vez más, el diseño del conjunto pretende manifestar el carácter añadido del mismo (fig. 24, 25).

Con independencia de la delicada restauración de las yeserías, otras dos operaciones requieren especial atención en la Galería de Mujeres. Una se refiere a la visión del techo de ésta desde la Sala de Oración. Visión, por otro lado, muy ligada a la de la propia artesa de la Sala. Debido a su ruinoso estado y a la necesidad de poder absorber las nuevas instalaciones, requería ser sustituido. Para ello, se diseña un techo suspendido y desmontable, capaz de adaptarse a la futura instalación museográfica, formado por perfiles omega entre cuyas alas se apoyan directamente tableros de bubinga (fig. 26, 27). Sombra de perfilería y color de madera que no se contradicen con los de la artesa.

La otra operación se refiere al tratamiento de la luz natural. El balcón y la ventana ajimezada existentes, dado que el paño en que se encuentran está orientado al Sur, introducen demasiada luz en la Galería y, consecuentemente, en la Sala. Se ciega el primero y la segunda, temerosos de provocar protestas aunque se trate de una dudosa interpretación realizada en 1970, se tamiza con una celosía. Temor fundado, pues este ocultamiento mereció la única queja que suscitó toda la intervención.

En los paramentos se fijaron y restauraron las yeserías existentes, y se incorporaron trozos de otras yeserías encontradas en los sótanos de la Casa del Greco. El resto se pintó y el suelo, como continuación de la escalera, se acabó con un entarimado de madera de haya vaporizada.

\section{La Sala de Oración}

Conforme al criterio de actuación antes expuesto, la intervención arquitectónica en este espacio hubiera sido la más pequeña de todo el conjunto de las obras si artesa y yeserías no fueran consideradas inherentes a la definición y concreción del espacio.

El estado de conservación del artesonado era estructuralmente bueno. Los
26. Galería de Mujeres restaurada: yeserías, paramentos, y la nueva definición del suelo entarimado y del techo técnico

27. Iluminación de las yeserías restauradas a través del nuevo techo técnico 

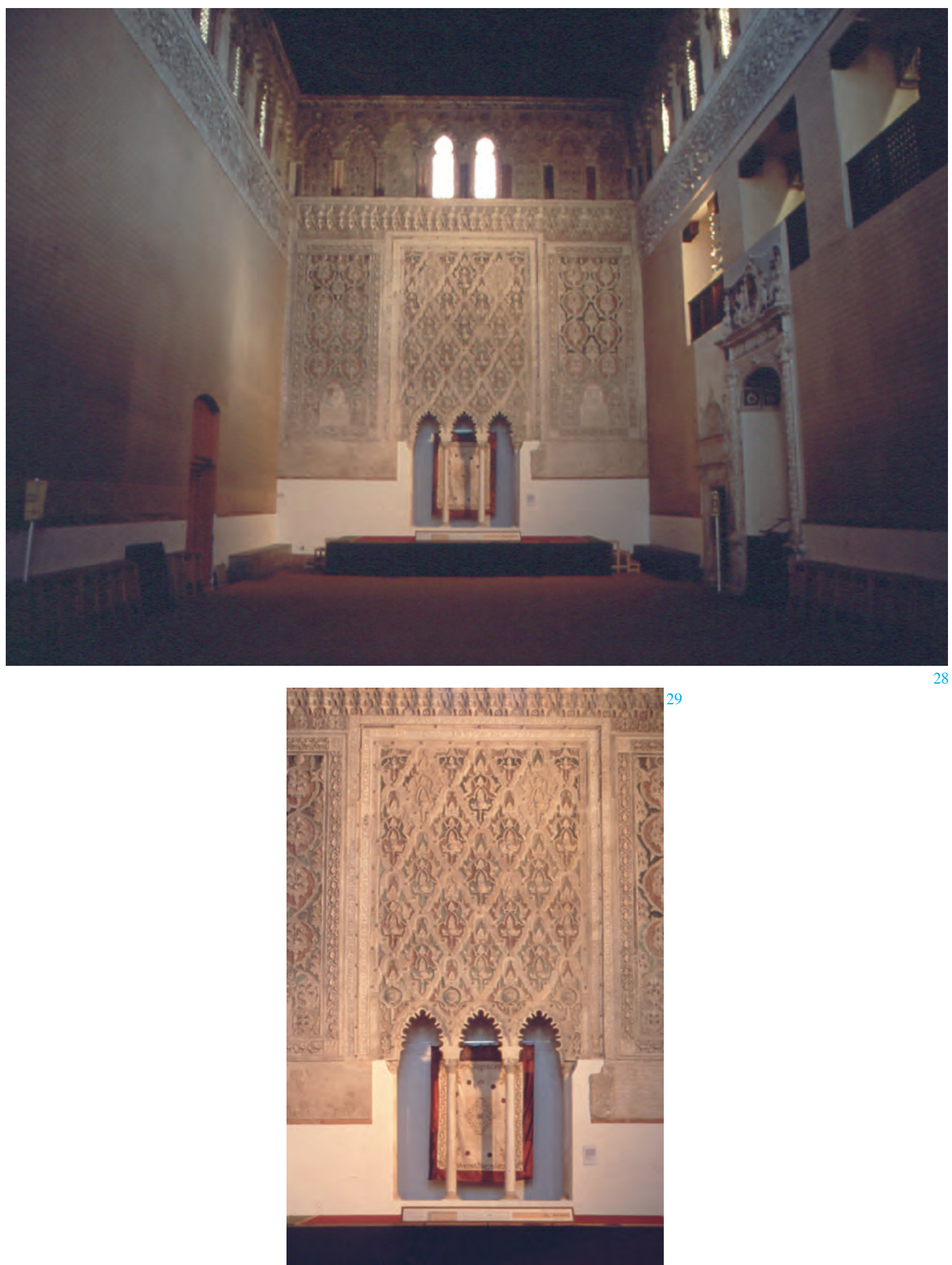

28. Sala de Oración. En el muro izquierdo se observa el hueco abierto entre Museo y Sala, aprovechando el arcosolio del altar oculto 29. Detalle del frente del Hejal una vez restaurado 


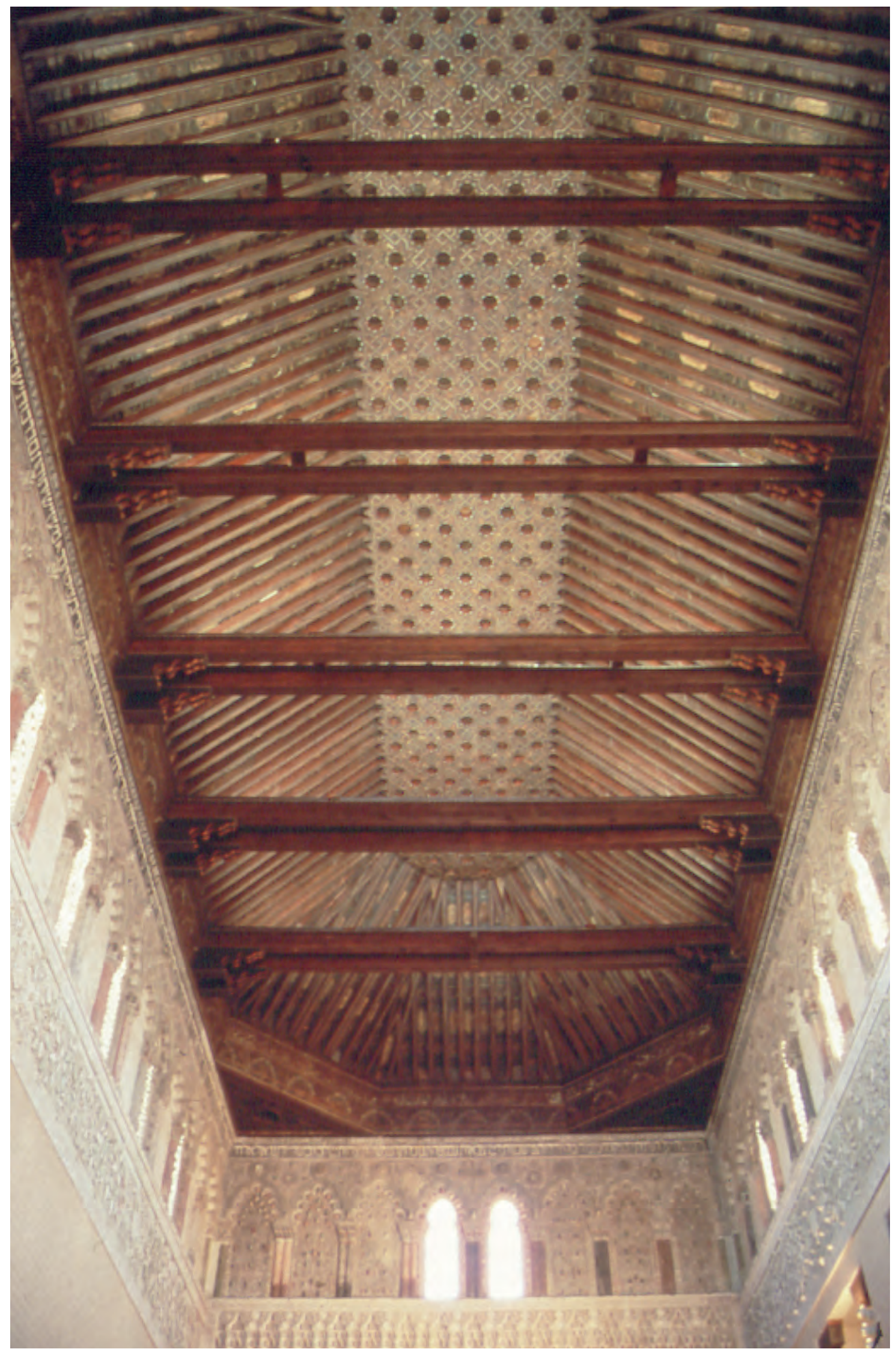

30. El artesonado se limpia y se unifica la coloración 
xilófagos detectados, y ya citados, no habían causado daños irreparables, pero obligaron a una desinsección previa a la restauración. Los lógicos movimientos de la madera, la oxidación natural y los humos, habían producido levantamientos de la capa pictórica, oscurecido colores y disminuidos los contrastes. La restauración efectuada entona las piezas no originales y aquellas que habían sufrido una fuerte pérdida de su coloración. La limpieza de la capa pictórica y la fijación de la policromía se efectúa con métodos tradicionales: disolventes orgánicos, colas animales, calor y presión.

En las yeserías el empuje del arriostramiento de la espadaña había provocado una grieta que, arrancando por debajo del arrocabe 1 , interesaba el vértice superior de una de las ventanas lobuladas. Por otro lado, en el montaje y desmontaje del retablo barroco que ocultaba el Hejal se produjeron diversos desperfectos en las yeserías del paramento Este. Aunque restauradas en su día, el desconocimiento de la lengua hebrea equivocó la recolocación de algunos de los trozos desprendidos. Los nuevos trabajos de restauración se realizaron en dos fases. En la primera se procedió a la limpieza, consolidación y tratamiento de las partes con peligro de desprendimiento. En la segunda se limpia y consolida la capa pictórica, se ejecuta una reintegración cromática, y se procede a una protección final de dicha capa.

Como continuación de los trabajos arqueológicos realizados en el patio trasero se ejecutó una prospección geoeléctrica del subsuelo de la Sala que arrojó la existencia de posibles restos de edificaciones anteriores.

Desde el punto de vista de la actuación meramente arquitectónica, la única obra ejecutada fue la apertura de un nuevo hueco de conexión entre el museo y la Sala. Hasta ese momento, el recorrido de las tres salas del museo se realizaba en fondo de saco, entrando y saliendo por la pequeña puerta citada con la Cruz de los Calatrava. Aunque la operación realizada en el patio permitía una circulación por el exterior hacia la Galería de Mujeres, resultaba obvia la necesidad de una que permitiera entrada y salida diferenciada a las estrechas salas del museo.

Modificar uno de los paramentos de la Sala de Oración resultaba inquietante. Las plantas de Palomares y Czekelius, y el grabado de Villamil facilitaron la coartada justificativa. En todos ellos se observa un altar embebido en el grueso muro de separación entre Sala y museo. En efecto, sobre una estela existente, y tras el entelado, apareció el hueco de dicho altar. Manteniendo la forma descubierta, se diseña una nueva puerta que posibilita la circulación requerida.

Seguros de que los tres grandes huecos cuadrados del paramento Oeste son una incorrecta apertura de Isidori, podríamos haber tenido la tentación de cegarlos. Conforme a los criterios enunciados, al no disponer de información suficiente que pudiera confirmar nuestra hipótesis, optamos por no alterarlos. Por otro lado, y aunque pensamos que su apertura modifica el planteamiento original de la iluminación del espacio, es cierto que desde el uso actual, en el que la propia Sala es el objeto expositivo, la cálida luz de poniente que la ilumina mejora la espacialidad (fig. 28, 29, 30 y 31).

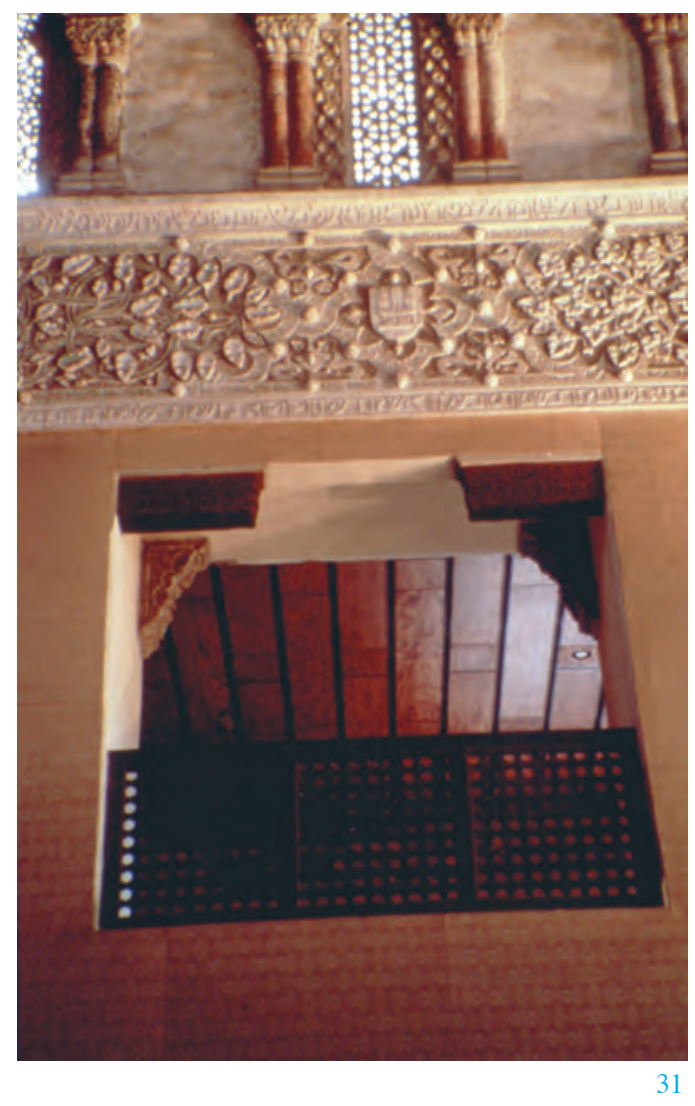

31. Vista Galería de Mujeres desde la Sala de Oración. Las ventanas tapadas por el campanario han recuperado su iluminación 


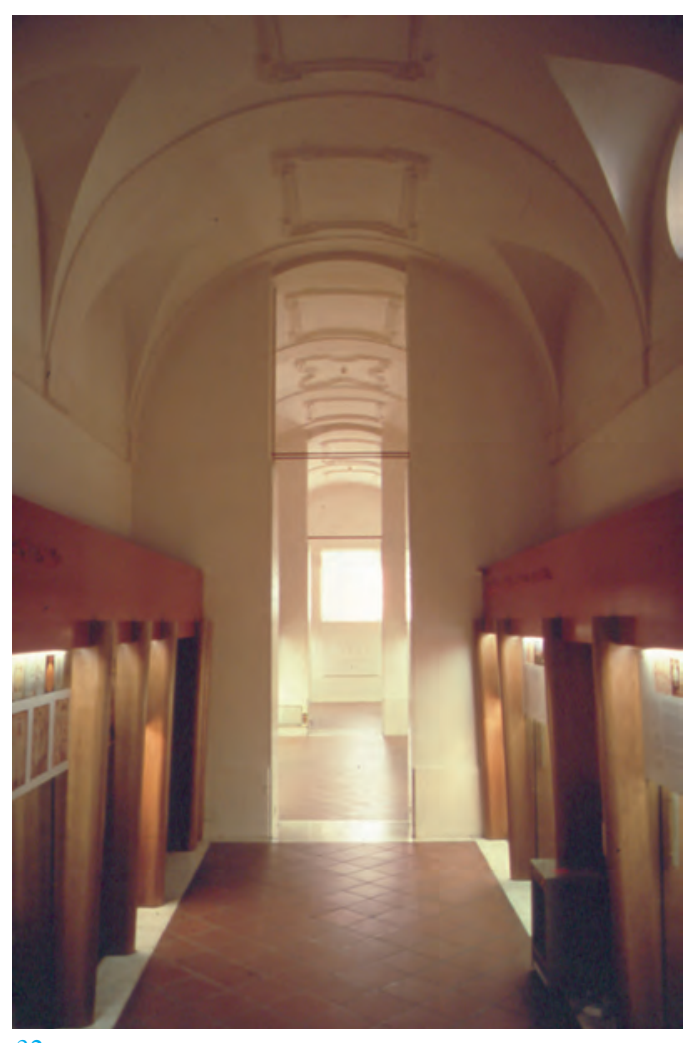

32

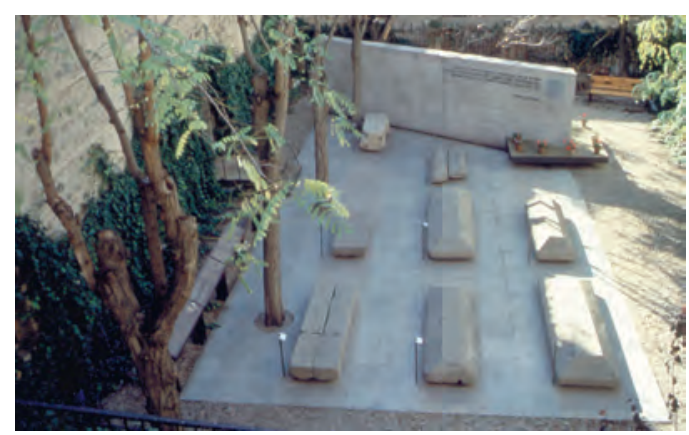

33

32. La escala espacial del Museo se modifica rasgando los muros transversales hasta las bóvedas. El atirantado del muro exterior queda al descubierto en los cortes introducidos

33. El jardín del Norte convertido en sala de exposición

\section{El Museo y el jardín}

Las fisuras existentes en los muros testeros y transversales del cuerpo Norte requerían modificar el sistema constructivo de la cubierta y su apoyo para evitar los empujes sobre la coronación del muro exterior. Para reforzar esta actuación se decide atirantar ese muro contra el de la Sala a la altura del arranque de la bóveda. Esta operación de atirantado, precisamente en los muros transversales, se acompaña con el rasgado de éstos en toda su vertical. Se pretende así modificar la configuración y escala del espacio del museo. Las tres salas antiguas, pequeñas y comunicadas por puertas de no más de dos metros de altura, se convierten en una sola, de mayor envergadura, aunque manteniendo la subdivisión primitiva (fig. 32).

Hasta aquí, todas las intervenciones descritas han procurado no modificar las estructuras existentes, limitándonos a operaciones de limpieza y clarificación, introduciendo elementos, cuando ha sido preciso, con carácter de adosamiento de los mismos. Por el contrario, en el museo, lo realizado sí pretende modificar la estructura espacial. Por un lado, como salas de exposición, se requería un cambio de escala. Por otra parte, la época de construcción de este cuerpo, siglo XVIII, admitía dicho cambio.

En el muro exterior se ciegan las ventanas que fueron abiertas cuando aquí se situó la vivienda del conserje, manteniendo solamente las que figuraban en los documentos consultados. Con ello se recupera la antigua imagen de la fachada al jardín, y se gana superficie de paramento para la futura instalación museográfica. Los suelos, de barro blando, se sustituyen, al igual que en el vestíbulo de acceso, por baldosas de ferrogrés con encintado y zócalo de piedra caliza, material que conforma los escalones de acceso al vestíbulo de las oficinas, define su suelo y se extiende hasta el nivel del patio trasero.

El "romántico" jardín, adyacente al cuerpo Norte, parecía el lugar adecuado para exponer las laudas sepulcrales que, por su tamaño, dificultaban la circulación en el interior del museo. Su asentada imagen como espacio abierto a la ciudad y la reja del Cristo de la Luz que lo delimita, rechazan un cierre opaco que lo conviertan en espacio interior del Museo Sefardí. Aceptando la permeabilidad visual, muy propia, por otra parte, de los espacios funerarios, se requiere, sin embargo, aumentar su seguridad y configuración. Para la primera se proyecta una nueva reja que, aunque mantiene ritmo y material con la existente, difiere en su diseño. La articulación entre una y otra se efectúa a través de un muro de ladrillo. La configuración se encomienda a un suelo de losas de granito gris y rosa y a un muro oblicuo respecto de la fachada, de granito rosa, que constituyen los soportes físicos de las piezas a exponer. El muro se plantea, en un principio, para recibir un texto y una serie de laudas verticales y privatizar el nuevo espacio en su visión desde la calle de los Reyes Católicos. La oblicuidad del mismo pretende lograr una mejor visualización desde la salida al jardín y dirigir la atención hacia el plano horizontal en el que se situarán las laudas tras su restauración.(fig. 33).

Escaleras, barandillas, etc. intentan una vez más distinguir, por su lenguaje y construcción, lo nuevo de lo antiguo.(fig. 34). 


\section{FICHA TÉCNICA DE LAS ACTUACIONES}

Realizado el Proyecto de Restauración, Remodelación y Acondicionamiento en 1.986, los trabajos encomendados terminaron en 1.992. Habían transcurrido 64 meses de obras previstas e imprevistas: limpiezas, consolidaciones, reestructuración, instalaciones, restauración de artesonados, yeserías y laudas, excavaciones arqueológicas, etc. Los iniciales $571 \mathrm{~m} 2$ de la Sinagoga se ampliaron con los $340 \mathrm{~m} 2$. del jardín y patio trasero, y los 292 m2 del pabellón para oficinas. El importe de lo ejecutado ascendió a casi 100 millones de pesetas. El Museo Sefardí quedó preparado para el Proyecto e instalación Museográfica. Se inauguró oficialmente el 1 de Junio de 1.993.

Organismo titular y Promotor:

Ministerio de Cultura. Dirección General de Museos del Estado.

Supervisión y Coordinación:

Carlos Baztán, Arquitecto de la Dirección Gral. de Museos del Estado.

Arquitectos autores del Pr. de Restauración y Rehabilitación, y Dirección de las Obras:

Carmen Bravo Durá.

Jaime Martínez Ramos.

Colaboradores: Javier García Vaquero, José Luis de Miguel, Consuelo Prados.

Arquitecto Técnico de la Obra:

Ángel Aparicio Olea.

Dirección técnica de las excavaciones:

Ana María López Álvarez.

Santiago Palomero.

Dirección técnica de las restauraciones:

Yeserías: Carmen Rallo.

Artesonado: Ana Carrasón.

Laudas sepulcrales: Ana Laborde y Concha Cirujano.

Asesoramiento técnico sobre la armadura y tratamiento de la madera:

Enrique Nuere.

Empresa constructora: COMSA.

\section{BIBLIOGRAFÍA BÁSICA.}

Monumentos Arquitectónicos de España.

La Sinagoga de Simuel-Ben-Meir Ha-Levi vulgarmente denominada "El Tránsito". Rodrígo Amador de los Ríos. 1.905.

Revue des études juives.

LXXXIV. Les synagoges de Tolède.

Elie Lambert. 1.927.

Arquitectura Año XIII. No 150 . Octubre 1.931

Otto Czekelius. Arquitecto.

Temas españoles.

Los sefardíes.

Jesús Cantera Ortíz de Urbina. Madrid. 1.965.

Sinagogas de Toledo, Segovia y Córdoba.

Francisco Cantera Burgos. Madrid. 1.973.

Catálogo del Museo Sefardí.

Ana María López Álvarez. 1.986.

Guía del Toledo judío.

Ana María López. Ricardo Izquierdo. Santiago Palomero. 1.990.

Sefarad.

Revista de estudios hebráicos, sefardíes y de Oriente Próximo.

Varios autores. Madrid. 1.992.
34. Detalle de la escalera de acceso al jardín desde el Museo

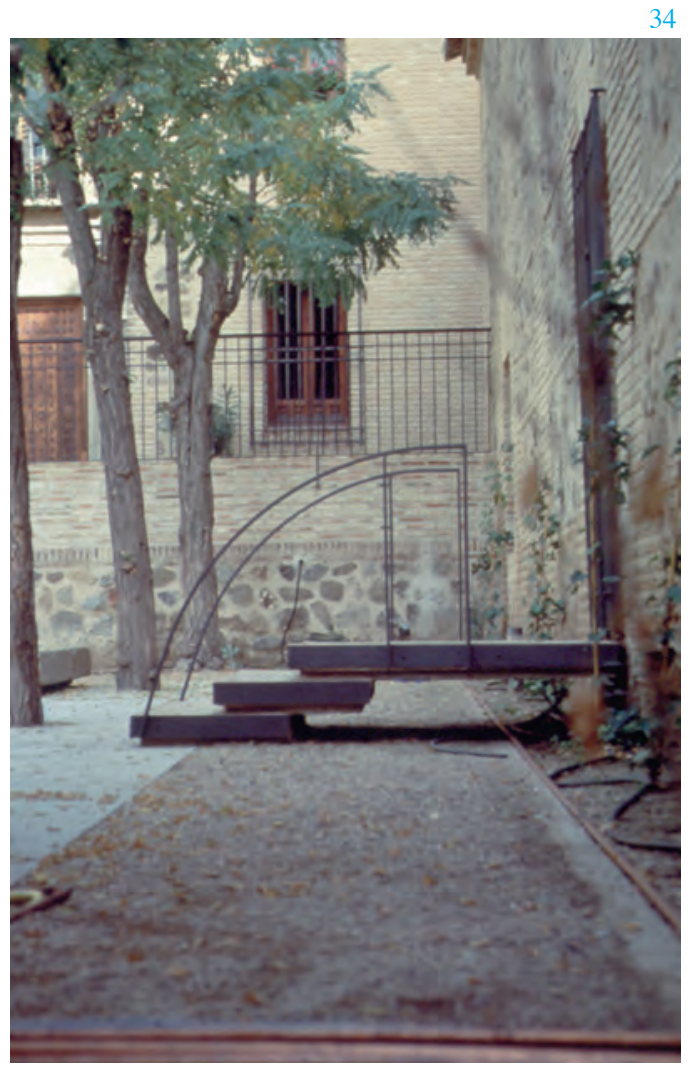




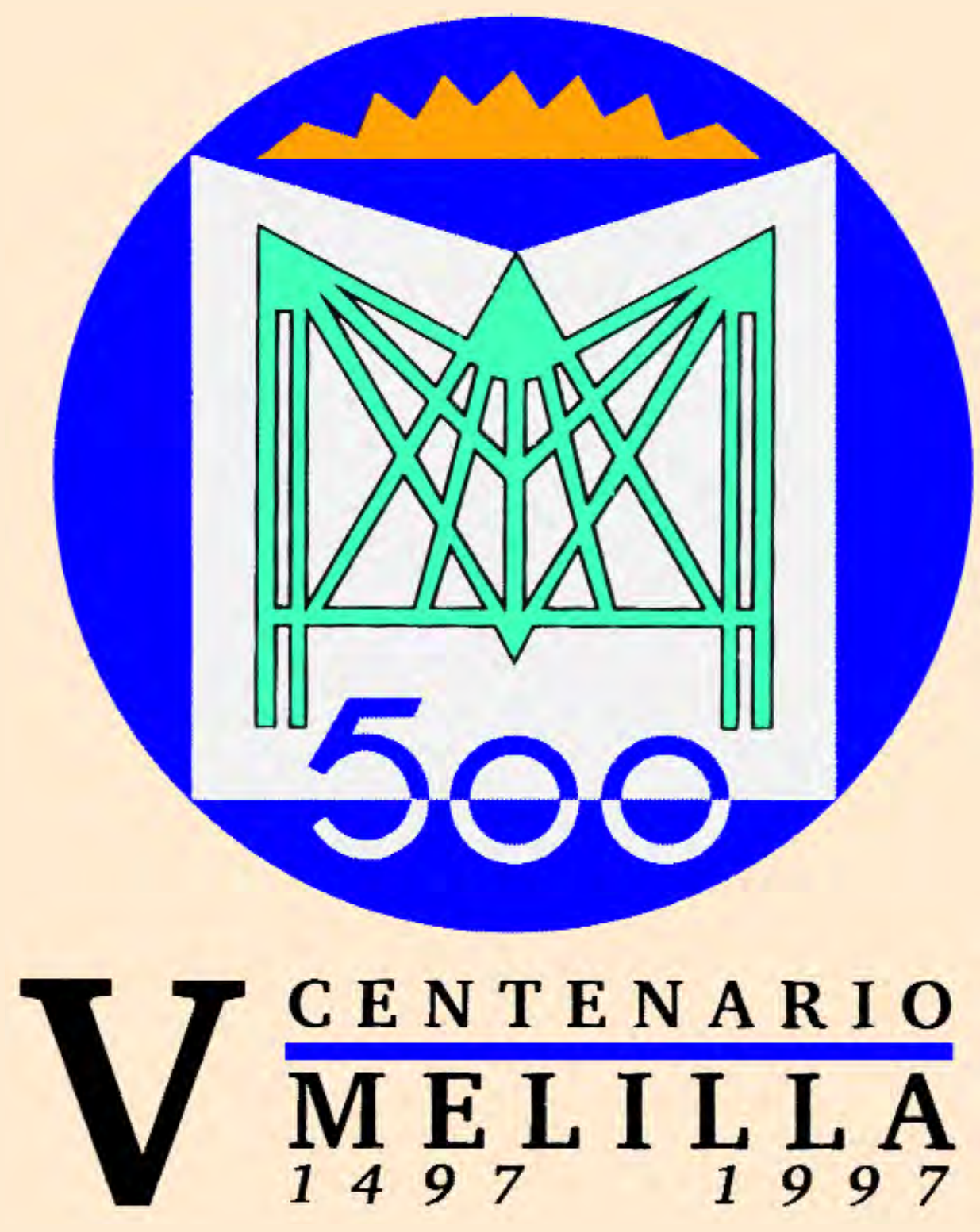

